Article

\title{
Chemical Composition and Biological Activities of the Nord-West Romanian Wild Bilberry (Vaccinium myrtillus L.) and Lingonberry (Vaccinium vitis-idaea L.) Leaves
}

\author{
Bianca-Eugenia Ștefănescu ${ }^{1,2}$, Lavinia Florina Călinoiu ${ }^{2, *(\mathbb{D},}$, Floricuța Ranga ${ }^{3}$, Florinela Fetea ${ }^{3}$, \\ Andrei Mocan ${ }^{1,4}\left(\mathbb{D}\right.$, Dan Cristian Vodnar ${ }^{3, *} \mathbb{0}$ and Gianina Crișan ${ }^{1}$ \\ 1 Department of Pharmaceutical Botany, "Iuliu Hațieganu” University of Medicine and Pharmacy, 23, Ghe. \\ Marinescu Street, 400337 Cluj-Napoca, Romania; stefanescu.bianca@umfcluj.ro (B.-E.Ș.); \\ mocan.andrei@umfcluj.ro (A.M.); gcrisan@umfcluj.ro (G.C.) \\ 2 Institute of Life Sciences, University of Agricultural Sciences and Veterinary Medicine Cluj-Napoca, Calea \\ Mănăştur 3-5, 400372 Cluj-Napoca, Romania \\ 3 Faculty of Food Science and Technology, University of Agricultural Sciences and Veterinary Medicine \\ Cluj-Napoca, Calea Mănăştur 3-5, 400372 Cluj-Napoca, Romania; florcutza_ro@yahoo.com (F.R.); \\ florinelafetea@yahoo.com (F.F.) \\ 4 Laboratory of Chromatography, Institute of Advanced Horticulture Research of Transylvania, University of \\ Agricultural Sciences and Veterinary Medicine, 400372 Cluj-Napoca, Romania \\ * Correspondence: lavinia.calinoiu@usamvcluj.ro (L.F.C.); dan.vodnar@usamvcluj.ro (D.C.V.)
}

Received: 4 April 2020; Accepted: 3 June 2020; Published: 5 June 2020

\begin{abstract}
This study was performed to evaluate and compare the in vitro antioxidant, antimicrobial, and antimutagenic activities, and the polyphenolic content of the Nord-West Romanian wild bilberry (Vaccinium myrtillus L.) and lingonberry (Vaccinium vitis-idaea L.) leaves from three different natural habitats (Smida, Turda, Borsa). In the case of both species, the flavanols level was higher in Smida habitat (altitude $1100 \mathrm{~m}$ ), whereas quercetin derivates were more abundant in Borsa habitat (altitude $850 \mathrm{~m}$ ). The bilberry leaf extracts contained in the highest amounts the feruloylquinic acid $(59.65 \pm 0.44 \mathrm{mg} / \mathrm{g}$ for Borsa habitat) and rutin $(49.83 \pm 0.63 \mathrm{mg} / \mathrm{g}$ for Borsa habitat), and showed relevant 2,2-diphenyl-1-picrylhydrazyl (DPPH) antioxidant activity (271.65 mM Trolox/100 g plant material for Borsa habitat, $262.77 \mathrm{mM}$ Trolox/100 g plant material for Smida habitat, and $320.83 \mathrm{mM}$ Trolox/100 g plant material for Turda habitat), for all the three extracts. Gallocatechin was the dominant flavanol in lingonberry species, with the highest amount being registered for Smida habitat $(46.81 \pm 0.3 \mathrm{mg} / \mathrm{g})$, revealing a DPPH antioxidant activity of $251.49 \mathrm{mM}$ Trolox/100 g plant material. The results obtained in the antimicrobial tests showed that the best inhibitory effect among bilberry species was attributed to the Turda (altitude $436 \mathrm{~m}$ ) and Smida locations, against both Gram-positive and Gram-negative bacterial strains. For lingonberry, the differences in habitat did not influence the antibacterial effect, but the antifungal effect, only in the case of Candida zeylanoides. A strong antimutagenic effect was registered by the bilberry leaves toward Salmonella typhimurium TA100. Our study may be able to provide a better understanding of the correlation between natural habitat conditions and the accumulation of secondary metabolites and their related bioactivities in studied leaves.
\end{abstract}

Keywords: bilberry; lingonberry; polyphenols; antioxidant compounds; antimicrobial activity; antimutagenicity; altitude variations 


\section{Introduction}

Most recent epidemiological studies have reported that certain medicinal plants can be responsible for preventing the development or evolution of several diseases [1-4]. The naturally-derived antioxidants are a topic of major interest considering their proven health effects on humans [2,5], but also to gradually replace the synthetic antioxidants that have been reported as endocrine disrupters or even carcinogenic compounds [6,7]. Dietary polyphenols have diverse therapeutic uses and several proven biological properties [1,8-11], being of important consideration to study their varieties in medicinal plants and natural foods [12].

The development of newly plant-derived functional products and nutraceuticals, known as edible sources with high antioxidant content, have been the intensively studied research topics in recent years [13]. Among them, Vaccinium species are constantly reported for their diversity in phenolic compounds [14-16], whereas cranberry (Vaccinium macrocarpon Ait.) and bilberry (Vaccinium myrtillus L.), being more debated than lingonberry (Vaccinium vitis-idaea L.), contributed to their high consumption rate under several forms: as fresh fruits, processed products, and dietary supplements. Recent literature reported that lingonberry occupies a significant position in the antioxidant and antimicrobial capacity ranking of Vaccinium-derived species [17,18].

Bilberry (Vaccinium myrtillus L.), also known as the European blueberry, and lingonberry (Vaccinium vitis-idaea L.), commonly known as cowberry or partridgeberry, are two small, spontaneous growing shrubs belonging to the genus Vaccinium, Ericaceae family. Their berries mature from July to September, while the ripeness time is highly affected by the site conditions, precisely altitude, and habitat type. Usually, higher altitudes generate later plant ripening when compared with lower elevations.

The bilberry and lingonberry leaves are the main by-products of berry harvesting and recent investigations [14,19] have reported a significantly higher content of phenolic compounds in the leaves and stems of Vaccinium species in contrast to the berries, in line with the strongest antioxidant activities registered by these aerial parts than fruits [20], indicating that they may be utilized as an alternative source of bioactive natural products for the development of food supplement, nutraceuticals, or functional food. Literature studies have shown that the leaves of bilberry and lingonberry contain fewer anthocyanins than fruits, but the content of phenolic compounds is higher in leaves than in fruits $[16,21,22]$. Several studies have reported the presence of hydroxycinnamic acids, flavonols, proanthocyanidins, cinchonains, and iridoids in the bilberry leaves [19,23-25]. Traditionally, bilberry leaves extracts are used for treating urinary tract affection and diabetes. Owing to the presence of various phenolic compounds, bilberry leaves also have antibacterial, anti-inflammatory, and antioxidant activities [26-28]. Chemical composition and biological properties of lingonberry leaves are similar to those of bilberry. Phenolic compounds found in lingonberry leaves are hydroxycinnamic acids, proanthocyanidins. flavonols, cinchonains, iridoids, and arbutin derivatives [14,23,27]. Extracts of lingonberry leaves have shown multiple beneficial diuretics and antiseptic properties for the urinary tract, anti-cough, phlegm removing, anti-inflammatory, neuroprotective, and antioxidant activity $[21,29,30]$.

The genetic factor must be considered when referring to polyphenol biosynthesis in the different parts of the plant, including leaves. Moreover, the biotic and abiotic conditions may be responsible for certain variations (increases or decreases) in phenolic concentration, as reported in the recent literature for bilberry leaf and stem [19,24] and lingonberry leaf [25,31]. A multitude of environmental factors change with the altitude of the growing site, precisely precipitation, mean temperature, soil, wind speed, low- and high-temperature extremes, duration of snow cover, length of vegetation period, and intensity of radiation under clear sky conditions. Enhanced UV-B radiation and lower temperatures at high altitudes have been constantly debated as having an impact on plant secondary metabolism [32,33]. As a protective mechanism towards damage induced by excessive UV-B radiation, plants support and stimulate the biosynthesis of UV-B-absorbing phenolic compounds with an 
antioxidant capacity [32,34]. The stimulation of enzymes responsible for flavonoid biosynthesis in UV-enhanced radiation experiments was highly underlined [35,36].

The latitude-related factor was discussed in particular for $V$. myrtillus L., being reported for the high influence on the quality and quantity of phenolic compounds [24,37-40], suggesting that higher phenolic amounts may be supported by northern latitudes, altitude, and sunny weather. However, most studies have aimed to investigate an individual morphological part of the bilberry plant, with fruits as most debated, and leaves in a small percentage. In this context, this study aims to provide a better understanding of the correlation between natural habitats and the accumulation of phenolic compounds in the leaves of Vaccinium myrtillus L. and Vaccinium vitis-idaea L. and their related bioactivities: antioxidant, antimicrobial, and antimutagenic. Thus, the investigation on the differences, derived from natural habitats within the same region (Nord-West), on polyphenolic content of the Romanian wild bilberry and lingonberry leaf extracts could be useful to broaden the knowledge on this field.

Considering that the chemical composition of the Nord-West Romanian wild bilberry and lingonberry leaves has never been the subject of a scientific paper to best of our knowledge, this study aimed to determine the phenolic composition of bilberry and lingonberry leaves and to measure their antioxidant, antibacterial, antifungal, and antimutagenic activities, whereas the antimutagenic and antimicrobial activities of the leaves are of significant novelty. Furthermore, the differences between the three different natural habitats of Romanian bilberry and lingonberry leaves were also investigated.

\section{Materials and Methods}

\subsection{Plant Samples and Growing Conditions}

The leaves of bilberry (Vaccinium myrtillus L.) and lingonberry (Vaccinium vitis-idaea L.) were collected in the autumn (September) of 2017 from spontaneous species of three different locations in Romania, differing in altitude and habitat type: (1) Turda $\left(46^{\circ} 32^{\prime} 00^{\prime \prime} \mathrm{N}, 23^{\circ} 52^{\prime} 00^{\prime \prime} \mathrm{E}\right)$, Cluj County; (2) Smida ( $46^{\circ} 38^{\prime} 33^{\prime \prime} \mathrm{N}, 22^{\circ} 52^{\prime} 49^{\prime \prime}$ E), Cluj County; and (3) Borsa ( $47^{\circ} 39^{\prime} 19^{\prime \prime} \mathrm{N}, 24^{\circ} 39^{\prime} 47^{\prime \prime}$ E), Maramures County. Leaves of both species were randomly sampled from ca. 10 shrubs in the same $20 \mathrm{~m} \times 20 \mathrm{~m}$ area for each habitat. The plant material was dried at room temperature for 7-10 days and grounded to a fine powder and kept in the dark prior to analyses. The results were calculated based on the dried and grounded plant material/powder. The numbers of Plant Voucher Specimens are VM103 and VVI105.

\subsection{Description of Habitats}

Turda is a municipality in the county of Cluj, Transylvania, Romania, and it is located about $30 \mathrm{~km}$ southeast of Cluj-Napoca. Turda developed mainly on the left side of the Aries river. The minimum altitude is $310 \mathrm{~m}$ in the eastern extremity, on the Aries valley, and the maximum is in the northeast of the city, on Slăninii Hill (436 m), from where the leaves were collected. The karst relief is present and develops into soluble rocks (limestone, salt, gypsum), being characterized by mineral soils. The climate in September is quite dry with $44 \mathrm{~mm}$ of rainfall, and involves a maximum temperature of $23^{\circ} \mathrm{C}$ and a minimum of $15^{\circ} \mathrm{C}$. The collection place had a moderate solar exposition considering the slope exposure [41].

Smida is located in the heart of the Apuseni Natural Park, a protected area that is among the last large areas of large, forested karst (spreading its wild beauty on approximately 76,000 hectares) throughout Europe. Smida village is at an altitude of $1100 \mathrm{~m}$ and benefits from a moderate continental climate, whereas in September, there is a maximum temperature of $23^{\circ} \mathrm{C}$ and a minimum of $1{ }^{\circ} \mathrm{C}$, with $6.5 \mathrm{~mm}$ of rainfall. The soil is characterized by acid brown soils with medium texture, and good aquatic drainage considering the winters rich in snow. It possesses large areas of natural forests and meadows, with a variety of fauna and flora. The relief is a karstic one, well developed, and made 
up of caves [42]. The collection place had partial sun exposure considering the open-spaced areas surrounded by forest.

The Borsa town is located in the south of Maramures county, Transylvania, Romania at an altitude of $850 \mathrm{~m}$ in the Rodnei Mountains, on the Vișeu river valley. The relief of the area is mountainous, very rugged, and with steep slopes and high-level differences, being characterized by the moderate continental climate sector, with a maximum temperature of $13{ }^{\circ} \mathrm{C}$ and a minimum of $8{ }^{\circ} \mathrm{C}$, and with the average annual rainfall of $1100 \mathrm{~mm}$ and permanent exposure to the advection of the western air masses of oceanic nature, whose characteristics are reflected in the evolution of all climatic elements. The collection place is characterized by acid brown soils and good solar exposition [43].

\subsection{Chemicals and Reagents}

Catechin, chlorogenic acid, quercetin, cyanidin chloride, and gallic acid used as standards for the HPLC-DAD-ESI-MS analysis were purchased from Sigma-Aldrich (Steinheim, Germany). Folin-Ciocalteu's phenol reagent, sodium carbonate (Na2CO3), sodium nitrate (NaNO2), hydrochloric acid $(\mathrm{HCl})$, aluminum chloride $(\mathrm{AlCl} 3)$, sodium hydroxide $(\mathrm{NaOH})$, acetic acid, acetonitrile, methanol, ethanol, DPPH (2,2-diphenyl-1-picrylhydrazyl), and Trolox (6-hydroxy-2,5,7,8-tetramethylchroman-2-carboxylic acid) were purchased from Sigma-Aldrich (Steinheim, Germany). For antimicrobial assays, Mueller-Hinton agar, thioglycollate broth with resazurin, and Mueller-Hinton broth were purchased from BioMerieux (France), and Tween 80 and Broth Malt medium were purchased from Sigma-Aldrich (Steinheim, Germany).

\subsection{Ultrasound-Assisted Extraction Procedure}

The fine powder obtained from the leaves $(0.25 \mathrm{~g})$ was extracted with $7 \mathrm{~mL} 40 \% v / v$ ethanol in water for $30 \mathrm{~min}$ in an ultrasonic bath, at $20^{\circ} \mathrm{C}$. After centrifugation $(5000 \mathrm{rpm}$ for $10 \mathrm{~min}$ at $24^{\circ} \mathrm{C}$ ), the supernatant was filtered and stored $\left(-18^{\circ} \mathrm{C}\right)$ until analysis (total phenolic content, total flavonoid content, total anthocyanin content, antioxidant, antimutagenic and antimicrobial activities, and HPLC-DAD-MS analysis).

\subsection{Analysis of Phenolic Compounds}

\subsubsection{HPLC-DAD-ESI-MS Analysis}

Identification and quantification of phenolic compounds in the leave extract were performed on an HPLC-DAD-ESI-MS system consisting of an Agilent 1200 HPLC with DAD detector, coupled to an MS-detector single-quadrupole Agilent 6110. For phenolic compounds' separation, the Eclipse column, XDB C18 $(4.6 \times 150 \mathrm{~mm}$, particle size $5 \mu \mathrm{m})$ (Agilent Technologies, USA), was used at $25^{\circ} \mathrm{C}$. The binary gradient was prepared from $0.1 \%$ acetic acid/acetonitrile (99:1) in distilled water $(v / v)$ (solvent $\mathrm{A}$ ) and $0.1 \%$ acetic acid in acetonitrile $(v / v)$ (solvent $B$ ) with a flow rate of $0.5 \mathrm{~mL} / \mathrm{min}$, according to the elution program described by Dulf et al. [44]. For MS fragmentation, the ESI (+) module was used, with a scanning range between 100 and $1200 \mathrm{~m} / \mathrm{z}$, capillary voltage $3000 \mathrm{~V}$, at $350^{\circ} \mathrm{C}$, and with a nitrogen flow of $8 \mathrm{l} / \mathrm{min}$. The eluent was monitored by DAD, and the absorbance spectra $(200-600 \mathrm{~nm})$ were measured and collected during each run. For analyzing the data, Agilent ChemStation Software (Rev B.04.02 SP1, Palo Alto, CA, USA) was performed. The phenolic compounds from the extracts were identified by comparing the retention times, UV visible, and mass spectra of the peaks with four reference standards, as follows: the compounds of the flavanol subclass were quantified using the calibration curve performed with catechin standard on the concentration ranges of 10-200 $\mu \mathrm{g} / \mathrm{mL}$ and expressed as equivalents of catechin (mg catechin/g plant material) $\left(r^{2}=0.9985\right)$; for the hydroxycinnamic acid subclass, the compounds were quantified using the calibration curve performed with chlorogenic acid on the concentration range of 10-50 $\mu \mathrm{g} / \mathrm{mL}$, expressed as chlorogenic equivalents (mg chlorogenic acid/g plant material) $\left(r^{2}=0.9937\right)$; flavonols were quantified using the calibration curve performed with quercetin on the concentration ranges of $10-200 \mu \mathrm{g} / \mathrm{mL}$, expressed as quercetin equivalents (mg 
quercetin/g plant material) $\left(r^{2}=0.9951\right)$; and anthocyanins were quantified using the calibration curve made with cyanidin on the concentration ranges of 10-100 $\mu \mathrm{g} / \mathrm{mL}$, expressed as cyaniding equivalents (mg cyanidin/g plant material) $\left(r^{2}=0.9951\right)$.

\subsubsection{Total Phenolic Content}

The determination of total phenolic content (TPC) was performed by the Folin-Ciocalteu method [44,45]. Briefly, $25 \mu \mathrm{L}$ of sample extract was combined with $125 \mu \mathrm{L}$ of Folin-Ciocalteu reagent $(0.2 \mathrm{~N})$ and $100 \mu \mathrm{L}$ of sodium carbonate solution $\left(\mathrm{Na}_{2} \mathrm{CO}_{3}, 7.5 \% w / v\right)$. Afterward, the mixture was incubated for $2 \mathrm{~h}$ in the dark at room temperature $\left(25^{\circ} \mathrm{C}\right)$. The absorbance was recorded at $760 \mathrm{~nm}$, using ethanol as blank. A standard curve was prepared using gallic acid $(0.01-1 \mathrm{mg} / \mathrm{mL})$, and the TPC in the extract was expressed as gallic acid equivalents (GAE) (mg GAE/100 g plant material).

\subsubsection{Total Flavonoid Content}

Total flavonoid content (TFC) was determined by a spectrophotometric method [46] based on the formation of a complex flavonoid-aluminum. Shortly, $1 \mathrm{~mL}$ of sample extract was mixed with $0.3 \mathrm{~mL}$ $\mathrm{NaNO}_{2}(5 \%)$; after $5 \mathrm{~min}, 0.3 \mathrm{~mL} \mathrm{AlCl} 3(10 \%)$ was added; afterward, $2 \mathrm{~mL} \mathrm{NaOH}(1 \mathrm{M})$ and water to a total volume of $10 \mathrm{~mL}$. The absorbance was measured immediately, at $510 \mathrm{~nm}$. A standard curve was prepared using quercetin $(0.117-1 \mathrm{mg} / \mathrm{mL})$ and the TFC was expressed as quercetin equivalents (QE) (mg QE/ 100 g plant material).

\subsubsection{Total Anthocyanin Content}

The total anthocyanin content (TAC) was determined by UV/visible spectrophotometric method [47]. The extracts were diluted with $40 \%$ ethanol, and the absorption was measured at $530 \mathrm{~nm}$ using a Jasco UV-VIS Spectrophotometer (V-530 double beam, Tokyo, Japan). The anthocyanin content was estimated as cyanidin-3-glucoside at $530 \mathrm{~nm}$ using a molar absorptivity coefficient of 26,900 and was expressed as milligrams per $100 \mathrm{~g}$ of plant material [47].

\subsection{DPPH Free-Radical-Scavenging-Assay}

DPPH free-radical-scavenging activity was performed using the method described by Ebrahimabadi et al. [48] with slight modifications. First, $250 \mu \mathrm{L}$ of each leaf hydroethanolic extract was mixed with $1750 \mu \mathrm{L}$ of freshly prepared DPPH solution ( $0.1 \mathrm{mM}$ in $40 \%$ ethanol). The absorbance was measured after $30 \mathrm{~min}$ of rest under dark conditions, at $517 \mathrm{~nm}$, using the spectrophotometer Biotek and $40 \%$ ethanol as blank. In the DPPH assay, the antioxidant activity of the extracts was evaluated using the calibration curve performed with Trolox, and then the absorbance was recorded for all the tested extracts, to calculate the percentage inhibition (expressed as percentage inhibition of the DPPH radicals). The percentage inhibition $(I \%)$ was calculated as $I \%=\left[\left(A_{B}-A_{A}\right) / A_{B}\right] \times 100$, where $A_{B}=$ absorbance of blank and $\mathrm{A}_{\mathrm{A}_{-}}=$absorbance of hydroethanolic extract.

\subsection{Antimicrobial and Antifungal Capacity}

\subsubsection{Stains and Cultivation Conditions}

To determine the antimicrobial activity for all extracts, six bacterial strains were used: three Gram-positive bacteria: Staphylococcus aureus (ATCC 49444), Enterococcus faecalis (ATCC 29212), Rhodococcus equi (ATCC 6939), and three Gram-negative bacteria: Pseudomonas aeruginosa (ATCC 27853), Klebsiella pneumonia (DSMZ 2026), Escherichia coli enterotoxigen (ATCC 25922). All tested microorganisms were obtained from the Food Biotechnology Laboratory, UASVM CN, Romania.

\subsubsection{Microdilution Technique}

Evaluation of the antimicrobial activity was done according to the guidelines of the Clinical Laboratory Standards Institute (CLSI) [49], using the standard broth microdilution technique for 
bacteria that grow aerobically, with slight modifications. Briefly, all the bacteria were cultured on Mueller-Hinton agar, followed by their storage at $4^{\circ} \mathrm{C}$ and subculture once a month. Before antibacterial susceptibility testing, each strain was inoculated on Mueller-Hinton agar plates and incubated at $37^{\circ} \mathrm{C}$ for $24 \mathrm{~h}$. The medium used for susceptibility testing was Mueller-Hinton broth. Inoculums (density of 0.5 in McFarland scale) were prepared in a $0.9 \% \mathrm{NaCl}$ sterile solution. Then, tested strains were suspended in Mueller-Hinton broth medium, to give a final density of $2 \times 10^{5}$ colony-forming units (CFU)/mL. The inoculum was stored at $4{ }^{\circ} \mathrm{C}$ for further use. Determinations of minimum inhibitory concentrations (MICs) were performed by a serial dilution technique using 96-well plates. The $100 \mu \mathrm{L}$ Mueller-Hinton broth was placed into each of the 96 wells of the microplates. Aliquots of $100 \mu \mathrm{L}$ of each extract (concentration of $0.1 \mathrm{~g} / \mathrm{mL}$ ) were added into the first rows of the microplates and twofold dilutions of the extracts were made by dispensing the solutions into the remaining wells. Then, $10 \mu \mathrm{L}$ of the culture suspensions was inoculated into the wells. We used ethanol $(40 \%)$ in water as a control. The microplates were incubated for $24-48 \mathrm{~h}$ at $37^{\circ} \mathrm{C}$. The MIC of the plant extracts was detected after the addition of $20 \mu \mathrm{L}(0.2 \mathrm{mg} / \mathrm{mL})$ of resazurin solution to each well, and the plates were incubated for $2 \mathrm{~h}$ at $37^{\circ} \mathrm{C}$. A change from blue to pink indicates the reduction of resazurin and, therefore, bacterial growth. The MIC was defined as the lowest concentration of the extract that inhibited the growth of the bacterial strain [50], which respectively prevented this color change. The minimum bactericidal concentrations (MBCs) were determined by serial subcultivation of $2 \mu \mathrm{L}$ into 96-well plates containing $100 \mu \mathrm{L}$ of Mueller-Hinton broth per well and further incubation for $48 \mathrm{~h}$ at $37^{\circ} \mathrm{C}$. The MBC was defined as the lowest concentration of the tested extract/compound/antibiotic killing the majority $(99.9 \%)$ of bacterial inoculum, thus with no visible growth [50]. Streptomycin (Sigma P 7794, Santa Clara, CA, USA) $(0.05-3 \mathrm{mg} / \mathrm{mL})$ was used as a positive control for bacterial growth. Water was used as a negative control.

\subsubsection{Antifungal Assay}

Evaluation of the antifungal activity was done according to the guidelines of the CLSI [51], using the reference method for broth dilution antifungal susceptibility testing of yeasts, with slight modifications. To determine the minimum inhibitory concentration (MIC) and minimum fungicidal concentration (MFC) of the tested extracts, three fungi were used: Candida albicans (ATCC 10231), Candida zeylanoides (ATCC 20367), and Candida parapsilosis (ATCC 22019). All the tested fungal strains were obtained from the above-mentioned source. The cultures were stored on malt agar at $4{ }^{\circ} \mathrm{C}$ and subcultured monthly. Before antifungal susceptibility testing, each strain was inoculated on malt agar plates to ensure optical growth characteristics and purity. The medium used for susceptibility testing was broth malt. The initial density of Candida spp. was approximately $2 \times 10^{6}$ colony-forming units $/ \mathrm{mL}(\mathrm{CFU} / \mathrm{mL})$. Inoculums (density of $0.5 \mathrm{in} \mathrm{McFarland} \mathrm{scale)} \mathrm{were} \mathrm{prepared} \mathrm{in} \mathrm{a} 0.9 \% \mathrm{NaCl}$ sterile solution. Then, tested strains were suspended in broth malt medium, to give a final density of $1.5 \times 10^{5} \mathrm{CFU} / \mathrm{mL}$. For the minimum inhibitory concentration test, the broth microdilution method was applied by preparing a serial of dilutions in 96-well plates. The $100 \mu \mathrm{L}$ medium was placed into each of the 96 wells of the microplates. Aliquots of $100 \mu \mathrm{L}$ of each extract diluted in $0.85 \%$ saline (concentration of $0.1 \mathrm{~g} / \mathrm{mL}$ ) were added into the first rows of the microplates, and twofold serial dilutions were made by dispensing the solutions into the remaining wells. Then, $10 \mu \mathrm{L}$ of the inoculum was added to the wells. Plates were incubated at $28^{\circ} \mathrm{C}$ for $72 \mathrm{~h}$ on a rotary shaker. Minimum inhibitory concentration (MIC) values were determined by adding resazurin $(20 \mu \mathrm{L}, 0.02 \%)$ followed by incubation for $2 \mathrm{~h}$. The MIC was defined as the lowest concentration required to inhibit the growth of the fungal strain (observed through a binocular microscope). The MFCs were determined by serial subcultivation of $2 \mu \mathrm{L}$ of tested extracts dissolved in medium and inoculated for $72 \mathrm{~h}$ into microtiter plates containing $100 \mu \mathrm{L}$ of broth per well, followed by further incubation $72 \mathrm{~h}$ at $28^{\circ} \mathrm{C}$. The lowest concentration with no visible growth was defined as the MFC, indicating the death of $99.9 \%$ of the original inoculum. The positive control used was fungicide fluconazole (1-3500 $\mu \mathrm{g} / \mathrm{mL}$ ) (Sigma F 8929, 
Santa Clara, CA, USA), while the negative control used was water. All the tests were done in duplicate and repeated thrice.

\subsection{Mutagenic and Antimutagenic Assay}

According to the plate incorporation method [52], described in more detail by Sarac and Sen [53], the plant extracts were tested for mutagenicity and antimutagenicity towards S. typhimurium TA98 and S. typhimurium TA100, whereas the positive controls used were 4-nitro-ophenylenediamine (4-NPD, $3 \mathrm{mg} /$ plate) for TA98 and sodium azide (NaN3, $8 \mathrm{mg} /$ plate) for TA100. The negative control was ethanol/water $(1: 1, v / v)$, and the concentration of plant extracts was established to $5 \mathrm{mg} / \mathrm{plate}$. According to the equation described by Ong et al. [54], the antimutagenicity was calculated as follows: \%Inhibition $=[1-\mathrm{T} / \mathrm{M}] \times 100$, where $\mathrm{T}$ is the number of revertants per plate in the presence of mutagen and the plant extract, and $\mathrm{M}$ is the number of revertants per plate without plant extract (positive control). The antimutagenicity of the reference mutagens in the absence of the plant extract was defined as $0 \%$ inhibition. For each of the two species, the testing was done in duplicate with three subsamples each, and in accordance, the data are reported as the mean \pm standard deviation (SD). The following percentage ranges were used to express the antimutagenicity: strong: $40 \%$ or more inhibition; moderate: $25-40 \%$ inhibition; low/none: $25 \%$ or less inhibition [55].

\subsection{Statistical Analysis}

All of the analyses were done in triplicate, and the data were reported as the means \pm standard deviation (SD). The statistical differences among the leave extracts of the three different locations for each type of species were performed using one-way analysis of variance (ANOVA) (Tukey multiple comparison tests) via GraphPad Prism Version 8.0.1 (Graph Pad Software Inc., San Diego, CA, USA). Differences between means at the $5 \%$ level were reported to be statistically significant.

\section{Results and Discussion}

\subsection{Phenolic Profile of Wild Bilberry and Lingonberry Leaves}

In this study, in the leaves of bilberry and lingonberry, 21 phenolic compounds were identified, originating from four phenolic groups: hydroxycinnamic acids, flavonols, flavanols, and anthocyanins, whereas 19 were found in bilberry leave extracts and 18 in lingonberry leave extracts (Table 1). In the case of bilberry leaves, the most abundant compounds for all three locations were represented by the flavonols class comprising only quercetin derivates. The second most abundant class was flavanols. For lingonberry leaves, the most abundant class of compounds was flavanols, as reported in the literature [56], for all the three different altitude habitats, followed by hydroxycinnamic acids. In the case of lingonberry leaves, the flavonols class registered small levels for each compound, except rutin. Moreover, the anthocyanins group was not detected. 
Table 1. The phenolic compounds content in the leaves of bilberry and lingonberry using HPLC-DAD-ESI-MS and expressed as mg/g.

\begin{tabular}{|c|c|c|c|c|c|c|c|c|c|c|}
\hline Phe & lic Compounds & $\begin{array}{c}\text { Retention } \\
\text { Time } \\
\mathbf{R}_{\mathbf{t}}(\mathrm{min})\end{array}$ & $\begin{array}{c}\mathrm{UV} \\
\lambda_{\max } \\
(\mathrm{nm})\end{array}$ & $\underset{(\mathrm{m} / \mathrm{z})}{[\mathrm{M}+\mathrm{H}]^{+}}$ & VMT & VMS & VMB & VVIT & VVIS & VVIB \\
\hline \multirow{7}{*}{ Flavanols } & Gallocatechin & 2.97 & 279 & 307,290 & $7.59 \pm 0.07^{b}$ & $15.37 \pm 0.14^{\mathrm{a}}$ & $4.84 \pm 0.05^{c}$ & $35.10 \pm 0.24^{b}$ & $46.81 \pm 0.38^{\mathrm{a}}$ & $31.41 \pm 0.21^{\mathrm{c}}$ \\
\hline & Epigallocatechin & 4.24 & 279 & 307,290 & n.d & $6.56 \pm 0.06$ & n.d & $25.24 \pm 0.72 \mathrm{~b}$ & $35.97 \pm 0.23^{a}$ & $23.35 \pm 0.61^{\mathrm{c}}$ \\
\hline & Catechin & 12.58 & 280 & 291 & $9.87 \pm 0.07^{\mathrm{a}}$ & $4.79 \pm 0.07^{c}$ & $5.38 \pm 0.09^{b}$ & $18.51 \pm 0.21^{b}$ & $21.57 \pm 0.2^{\mathrm{a}}$ & $17.43 \pm 0.18^{b}$ \\
\hline & Epicatechin & 13.11 & 280 & 291 & $4.31 \pm 0.03^{b}$ & $9.66 \pm 0.08^{\mathrm{a}}$ & n.d & n.d & n.d & $2.78 \pm 0.03$ \\
\hline & Procyanidin dimer I & 11.33 & 280 & 579,291 & n.d & n.d & n.d & $6.38 \pm 0.05^{\mathrm{b}}$ & $8.36 \pm 0.06^{\mathrm{a}}$ & $6.27 \pm 0.03^{b}$ \\
\hline & Procyanidin dimer II & 19.74 & 280 & 579,291 & $12.68 \pm 0.11^{\mathrm{a}}$ & $12.13 \pm 0.12^{\mathrm{a}}$ & $8.70 \pm 0.07^{b}$ & $2.20 \pm 0.05^{\mathrm{b}}$ & $4.23 \pm 0.04^{\mathrm{a}}$ & $4.61 \pm 0.03^{\mathrm{a}}$ \\
\hline & Procyanidin trimer & 13.89 & 280 & 865,291 & $21.84 \pm 0.21^{b}$ & $24.30 \pm 0.72^{\mathrm{a}}$ & $10.09 \pm 0.12^{\mathrm{c}}$ & $12.92 \pm 0.12^{\mathrm{c}}$ & $14.21 \pm 0.16^{\mathrm{b}}$ & $18.84 \pm 0.22^{\mathrm{a}}$ \\
\hline \multirow{4}{*}{$\begin{array}{l}\text { Hydroxycinnamic } \\
\text { acids }\end{array}$} & Chlorogenic acid & 12.01 & 281,329 & 355,163 & $3.34 \pm 0.03^{c}$ & $3.85 \pm 0.02^{b}$ & $5.94 \pm 0.05^{\mathrm{a}}$ & $0.79 \pm 0.01^{\mathrm{b}}$ & n.d & $1.16 \pm 0.01^{\mathrm{a}}$ \\
\hline & Feruloylquinic acid & 14.79 & 283,330 & 369 & $55.37 \pm 0.42^{b}$ & $47.66 \pm 0.39^{c}$ & $59.65 \pm 0.44$ a & $31.05 \pm 0.18^{b}$ & $24.61 \pm 0.24^{c}$ & $33.42 \pm 0.37^{a}$ \\
\hline & Caffeoylarbutin & 17.20 & 288,330 & 435 & n.d & n.d & n.d & $6.45 \pm 0.04^{\mathrm{a}}$ & $3.42 \pm 0.02^{c}$ & $5.14 \pm 0.05^{b}$ \\
\hline & Dicaffeoylquinic acid & 20.08 & 282,329 & 517,163 & $5.01 \pm 0.05^{\mathrm{a}}$ & $4.05 \pm 0.04^{\mathrm{b}}$ & n.d & $1.77 \pm 0.02^{\mathrm{a}}$ & $0.93 \pm 0.01^{b}$ & $1.74 \pm 0.01^{\mathrm{a}}$ \\
\hline \multirow{7}{*}{$\begin{array}{c}\text { Flavonols } \\
\text { (quercetin } \\
\text { derivatives) }\end{array}$} & Quercetin-rutinoside (Rutin) & 15.35 & 263,355 & 611,303 & $44.91 \pm 0.21^{\mathrm{b}}$ & $42.34 \pm 0.19^{c}$ & $49.83 \pm 0.63^{a}$ & $18.61 \pm 0.19^{b}$ & $11.45 \pm 0.10^{c}$ & $21.88 \pm 0.19^{\mathrm{a}}$ \\
\hline & Quercetin-glucoside & 16.20 & 263,355 & 465,303 & $1.42 \pm 0.01 \mathrm{~b}$ & $1.29 \pm 0.01^{\mathrm{c}}$ & $2.37 \pm 0.02^{\mathrm{a}}$ & $3.05 \pm 0.03^{\mathrm{a}}$ & $2.23 \pm 0.03^{b}$ & $1.91 \pm 0.02^{\mathrm{c}}$ \\
\hline & Quercetin-acetyl-rhamnoside & 17.83 & 263,356 & 493,303 & $18.60 \pm 0.16^{\mathrm{a}}$ & $12.67 \pm 0.10^{c}$ & $15.47 \pm 0.14^{b}$ & $6.10 \pm 0.04^{\mathrm{b}}$ & $1.71 \pm 0.01^{\mathrm{c}}$ & $8.01 \pm 0.07^{\mathrm{a}}$ \\
\hline & Quercetin-arabinoside & 18.69 & 262,355 & 435,303 & $1.55 \pm 0.01^{\mathrm{a}}$ & $1.53 \pm 0.01^{\mathrm{a}}$ & $1.39 \pm 0.01 \mathrm{~b}$ & $0.41 \pm 0.01^{\mathrm{b}}$ & $0.07 \pm 0.01^{\mathrm{c}}$ & $0.61 \pm 0.01^{\mathrm{a}}$ \\
\hline & Quercetin-xyloside & 18.98 & 262,355 & 435,303 & $1.47 \pm 0.01 \mathrm{~b}$ & $1.30 \pm 0.01^{\mathrm{c}}$ & $1.53 \pm 0.01^{\mathrm{a}}$ & $0.45 \pm 0.01^{\mathrm{b}}$ & $0.05 \pm 0.01^{\mathrm{c}}$ & $0.62 \pm 0.01^{\mathrm{a}}$ \\
\hline & Quercetin-diglucoside & 21.15 & 263,355 & 628,303 & $0.91 \pm 0.01^{\mathrm{c}}$ & $1.42 \pm 0.01^{\mathrm{a}}$ & $0.17 \pm 0.01^{\mathrm{b}}$ & $3.11 \pm 0.03^{b}$ & $3.93 \pm 0.05^{\mathrm{a}}$ & $1.12 \pm 0.01^{\mathrm{c}}$ \\
\hline & Quercetin & 21.88 & 261,355 & 303 & $3.69 \pm 0.03^{a}$ & $3.26 \pm 0.04^{\mathrm{b}}$ & $1.16 \pm 0.06^{\mathrm{c}}$ & $4.78 \pm 0.04^{\mathrm{a}}$ & $3.31 \pm 0.02^{b}$ & $2.61 \pm 0.02^{\mathrm{c}}$ \\
\hline \multirow{3}{*}{ Anthocyanins } & Cyanidin-glucoside & 11.02 & 210,517 & 449,287 & $0.28 \pm 0.01^{\mathrm{a}}$ & $0.29 \pm 0.01^{\mathrm{a}}$ & n.d & n.d & n.d & n.d \\
\hline & Cyanidin-arabinoside & 11.78 & 214,517 & 419,287 & n.d & $0.30 \pm 0.01$ & n.d & n.d & n.d & n.d \\
\hline & Cyanidin-acetyl-glucoside & 14.28 & 218,518 & 491,287 & $0.33 \pm 0.01^{\mathrm{a}}$ & $0.29 \pm 0.01^{b}$ & n.d & n.d & n.d & n.d \\
\hline
\end{tabular}

Values (expressed as mean values $\pm \mathrm{SD}, \mathrm{mg} / \mathrm{g}, n=3$ ) in the same row followed by different letters (a-c) indicate significant differences ( $p<0.05)$ between the three different locations, individual for each type of species (one-way analysis of variance (ANOVA); multiple comparison test; Tukey multiple range test $(p=0.05)$; GraphPad Prism Version 8.0.1, Graph Pad Software, Inc., San Diego, CA, USA). VMT, V. myrtillus leaves from Turda; VMS, V. myrtillus leaves from Smida; VMB, V. myrtillus leaves from Borsa; VVIT, V. vitis-idaea leaves from Turda; VVIS, V. vitis-idaea leaves from Smida; VVIB, V. vitis-idaea leaves from Borsa; n.d, not detected. 
The flavanols identified among the two studied species were catechin, epicatechin, gallocatechin, epigallocatechin, two procyanidin dimers, and procyanidin trimer. The procyanidin dimers and trimers are known as proanthocyanidins as well.

In the case of bilberry leaves, for almost all flavanols, the V. myrtillus leaves from Smida (VMS) reported the highest amounts. Exceptions were catechin and procyanidin dimers II, in which case $V$. myrtillus leaves from Turda (VMT) presented significantly higher values. The major flavanol identified was procyanidin trimer in all three natural habitats, whereas the VMS had the highest value ( $24.30 \pm 0.72 \mathrm{mg} / \mathrm{g}$ plant material), closely followed by VMT, while V. myrtillus leaves from Borsa (VMB) registered a 2.5-fold lower value. In particular, gallocatechin was twofold more in VMS than VMT and threefold more when compared with VMB. Epigallocatechin presence only in VMS contributes to the range of differences found among the three different locations. Procyanidin dimer I was not detected in the bilberry leaves of any of the three habitats, whereas epicatechin was the minor compound identified. The VMB leaves had the lowest values among all the flavanols identified, whereas epigallocatechin, epicatechin, and procyanidin dimer I were not present. Compounds present in lower proportions were catechins, in line with the previous results on bilberry leaves from Northern Europe [24]. Significant differences in gallocatechin, epigallocatechin, epicatechin, and procyanidin trimer were detected among locations, and up to threefold higher levels (in the case of gallocatechin) were measured, which can be linked to specific growth conditions of the sites (soil, solar exposure, microclimatic conditions). The habitat can specifically influence the amounts of phenolics as follows: either by the influence of pedological or climatic factors and their interactions [57]. Likewise, Martz et al. [24] reported that high-light-intensity location, higher altitudes, and/or latitudes contributed to more than twofold higher levels of phenolics in the leaves in contrast to lower altitudes or low-light-intensity sites.

Exceptionally high levels of flavanols were quantified in lingonberry leaves, in agreement with the results of previous studies [14,16,56,58], whereas the most recent study of Tian et al. [59] found, as the two most common flavanols, (+)-catechin and (-)- epicatechin, at the highest level in lingonberry (V. vitis-idaea) leaf extract $(118 \mathrm{mg} / 100 \mathrm{~mL})$. In our study, gallocatechin was quantified in high amounts, whereas epigallocatechin was detected in significant levels ranging from $23.35 \pm 0.61$ to $35.97 \pm 0.23$ depending on the habitat. Their occurrence has never been reported in lingonberry so far, only in bilberry leaves [23] and bilberry stems [19]. However, Bujor et al. [14] reported only a trace amount in lingonberry leaves and quantified the gallocatechin in lingonberry stems. In our study, V. vitis-idaea leaves from Smida (VVIS) registered the highest values among almost all the flavanols identified, except for procyanidin trimer and procyanidin dimer II. Gallocatechin was the major flavanol identified in all the three locations, whereas VVIS had the highest amount $(46.81 \pm 0.38 \mathrm{mg} / \mathrm{g}$ plant material), while epigallocatechin and catechin were close behind. Epicatechin was the minor compound identified, and only in V. vitis-idaea leaves from Borsa (VVIB); moreover, VVIB registered the highest values for procyanidin dimer II and procyanidin trimer. Furthermore, recent literature reported rich contents of procyanidin dimers and trimers in the extracts of lingonberry leaf $(85 \mathrm{mg} / 100 \mathrm{~mL})$ [59]. All these results underline that rising concentrations of flavanols and especially gallocatechin, epigallocatechin, and catechin in lingonberry leaves, as well as procyanidin trimer in bilberry leaves, were observed in the habitats with higher altitude. This fact was explained in the previously reported results, whereas an increase of flavonoids level with elevation in herbal plants [60] and bilberry leaves [24] was registered. According to the literature, catechin dominated in the red berries, lingonberry, and cranberry, while epicatechin dominated in blue and blackberries [56], in agreement with our findings.

V. vitis-idaea L. yielded greater amounts of gallocatechin, epigallocatechin, catechin, and procyanidin dimer I with increasing altitude and its related climatic and soil conditions, except lower levels were found at the altitudes of 1100 when compared with $850 \mathrm{~m}$ in the case of procyanidin dimer II and procyanidin trimer (Table 1). The variation of the flavonoid fraction turned out to be closely related to the altitude-derived conditions, because we found the percentages of four out of six flavonoid compounds rising significantly at the highest altitude. It can be concluded that environmental 
factors at higher altitudes lead to elevated levels of flavanols, with gallocatechin and epigallocatechin above all, in dried and grounded lingonberry leaves.

Hydroxycinnamic acids are the most widespread phenolic acids in plants, which are described as cinnamic acid-derived compounds. Four derivates of hydroxycinnamic acid were identified: chlorogenic acid, feruloylquinic acid, dicaffeoylquinic acid, and caffeoylarbutin. In the case of bilberry species, VMB together with its environmental-derived conditions (good solar exposure, acid brown soil, low-temperature range) presented the highest levels among the four compounds, except for caffeoylarbutin and dicaffeoylquinic acid, which were not detected. The major compound reported was feruloylquinic acid (59.65 $\pm 0.44 \mathrm{mg} / \mathrm{g}$ plant material in VMB), followed by chlorogenic acid $(5.94 \pm 0.05 \mathrm{mg} / \mathrm{g}$ plant material in VMB) as 10-fold less than feruloylquinic acid. The study of Martz et al. [24] indicated that bilberry leaves from higher latitudes and higher altitudes (boreal forests in Finland, thus low solar exposure) had lower levels of chlorogenic acid derivatives. In the recent paper investigating the Finnish bilberry ( $V$. myrtillus L.) leaf extract, hydroxycinnamic acid derivatives represented $82 \%$ of the total content of phenolics, mostly as 3-O-caffeoylquinic acid, whereas other hydroxycinnamic acids (coumaric acid, caffeic acid, and ferulic acid) were identified as esters of acids or hexoses [59].

Concerning the lingonberry species, a specific hydroxycinnamic acid was found, precisely the caffeoylarbutin (not detected in bilberry leaves), with an increase of three- to fourfold when compared with dicaffeoylquinic acid, depending on the location. Similarly, Liu et al. [25], Tian et al. [16], and Hokkanen et al. [23] found 2-caffeoylarbutin as the major caffeic acid derivative. The lowest levels of all hydroxycinnamic acids were reported for VVIS, whereas the highest levels were reported for VVIB (caffeoylarbutin). The major compound was again feruloylquinic acid (33.42 $\pm 0.37 \mathrm{mg} / \mathrm{g}$ plant material), as almost half the amount when compared with bilberry species.

Bidel et al. [61] found that the amount of hydroxycinnamic acid highly increased with a higher photosynthetic active radiation (PAR) level, while Li et al. [62] also reported a comparable pattern in apple peel. Hydroxycinnamic acids protect the fundamental tissues from adverse UV radiation; therefore, their expanded accumulation in intense light exposure is anticipated [36]. The high UV-B exposure at higher altitudes is the key determinant for the increased synthesis of phenolic acids in plants [63]. Moreover, lower temperatures at higher altitudes also sustain secondary metabolism [33,37], particularly the accumulation of hydroxycinnamic acids. Following all the above, the Borsa habitat, characterized by a good solar exposure, low-temperature range, and brown acid soils, may explain the highest levels of hydroxycinnamic acids when compared with a moderate/partial solar irradiation and higher temperature ranges (characterizing the other two habitats).

From the flavonols group, seven phenols were identified, all were quercetin derivatives: quercetin, quercetin-rutinoside (rutin), quercetin-glucoside, quercetin-acetyl-rhamnoside, quercetin-arabinoside, quercetin-xyloside, and quercetin-diglucoside. The major flavonol identified within both species was quercetin-rutinoside (rutin), being approximately 40 times higher than most of the flavonols compounds identified, and about 2 times higher than quercetin-acetyl-rhamnoside. Among studied bilberry leaves, VMB presented the highest level $(49.83 \pm 0.63 \mathrm{mg} / \mathrm{g}$ plant material), where all the extracts showed a level above $40 \mathrm{mg} / \mathrm{g}$ plant material. Concerning the lingonberry leaves, again, VVIB has shown the highest amount $(21.88 \pm 0.19 \mathrm{mg} / \mathrm{g}$ plant material), where VVIS was half of this level. The second major flavonol compound identified in both species was quercetin-acetyl-rhamnoside with VMT presenting the highest amount $(18.60 \pm 0.16 \mathrm{mg} / \mathrm{g}$ plant material) in the bilberry species, and VVIB in the lingonberry species $(8.01 \pm 0.01 \mathrm{mg} / \mathrm{g}$ plant material). In the case of almost all flavonol compounds, the Smida location (1100 $\mathrm{m}$ altitude) reported the lowest values. These results suggest that a Borsa habitat-type (altitude $850 \mathrm{~m}$, good solar exposure, low-temperature range, brown acid soils) may be more beneficial for the biosynthesis of major flavonols compounds, whereas a good solar exposure (low forest environment) may positively contribute to flavonols level. The existing literature [19] on bilberry leaves reported, as major flavonols compound, the quercetin glycosides, namely, quercetin-3-O-galactoside, quercetin-3-O-glucoside, quercetin hexuronides, quercetin pentosides, and a quercetin rhamnoside. 
Moreover, the specific quercetin-3-O-(400-(3-hydroxy-3-methyl glutaryl))-a-rhamnoside was identified in all of the morphological parts studied, being previously reported in leaves by Hokkanen et al. [23] and Ieri et al. [27]. In the study of Bujor et al. [14], investigating the lingonberry leaves, a range of $12-19 \%$ flavonols were found. There were 18 quercetin glycosides identified, whereas the quercetin-3-O-galactoside, quercetin-3-O-glucoside, quercetin rutinoside, quercetin pentosides, and quercetin-3-O-rhamnoside were in line with previous findings $[16,23,25]$ and our study.

Concerning the anthocyanins class, the three anthocyanins identified were cyanidin-glucoside, cyanidin-arabinoside, and cyanidin-acetyl-glucoside. The anthocyanins group was present only in VMT and VMS leave extracts, but in a small amount $(<0.35 \mathrm{mg} / \mathrm{g})$. Our findings are in agreement with the study of Jaakola et al. [36], where elevated gene expression and, therefore, flavonoid biosynthesis including cyanidin glycosides owing to an increased UV exposure in bilberry leaves was described. Therefore, an assumption that anthocyanins from both bilberry leaves may have occurred in higher amounts with increased solar radiation can be made, if we consider the presence of cyanidin-arabinoside only in VMS. When compared with their related berries [64], anthocyanin synthesis is highly affected by light exposure and, as a consequence, bilberries from shaded sites [40] contained lower amounts of red pigments, as low light conditions limit photosynthetic activity. The mechanism involves firstly a decrease in carbohydrate synthesis, followed by a low level of substrate generated for secondary metabolism. Certain phenolic classes are then downregulated, with anthocyanin synthesis negatively influenced. Li et al. [62] also found that anthocyanin level as well as the flavonol content and activity of phenylalanine ammonia-lyase (PAL), and certain enzymes, were increased in the sun-exposed apple peel compared with the shaded peel, underlying the upregulation of the phenylpropanoid pathway generated by a favorable light condition. Rieger et al. [60] reported that the anthocyanins level in bilberries decreased with increasing altitude, while Roslon et al. [65] did not found a relationship between the content of anthocyanins in bilberry fruits and the position of habitats at different altitudes. In the same study, the leaves anthocyanins were not investigated as they were considered not specific for leaves.

\subsection{Total Phenolics and Total Flavonoids}

According to Figure 1A, the TPC among both species was very similar, whereas there were no statistical differences between the three types of lingonberry leaves. In the case of bilberry leaves, the highest level of TPC was registered by VMT with 13,588.95 $\pm 9.25 \mathrm{mg}$ GAE/100 g plant material $(135.8 \pm 9.25 \mathrm{mg} \mathrm{GAE} / \mathrm{g}$ plant material), being significantly different only from VMS, but not from VMB. In the study of Bujor et al. [19], on the same period of vegetation (September), for the bilberry leaf extracts, a TPC of $142.9 \pm 19.2$ (mg GAE/g dry extract) was reported, while in the most recent study on lingonberry of the same author [14], the lingonberry leaves extract shown a TPC of $158.9 \pm 6.0$ (mg GAE/g dry extract). These results are in the same range as our findings. Nevertheless, the Vaccinium plants have the same Romanian origin, but different habitats and environmental factors. In the study of Tian et al. [59], the lingonberry leaf ethanolic extracts showed a TPC of $859.5 \pm 9.9$ (GAE mg/100 mL), while for bilberry leaf ethanolic extracts, a TPC of $201.7 \pm 18.2$ (GAE mg/100 mL) was found. A possible explanation for the evident differences in contrast to our results may lie in the geographical location, Finnish versus Romanian. According to the same study [59], a higher value of Folin-Ciocalteau was found in the extracts from leaves than in the extract from berries and branches, and the leaf extracts showed higher antioxidative activities (3-20-fold in ORAC assay, 10-20 fold in TRAP) than the berry extracts, in association with the higher contents of phenolic compounds in the leaf extracts [59]. However, regarding our findings, it may be stated that the different habitats did not statistically influence the TPC of both bilberry and lingonberry leaves, considering the high fluctuation in amounts in the different phenolic sub-classes among the three different locations. 

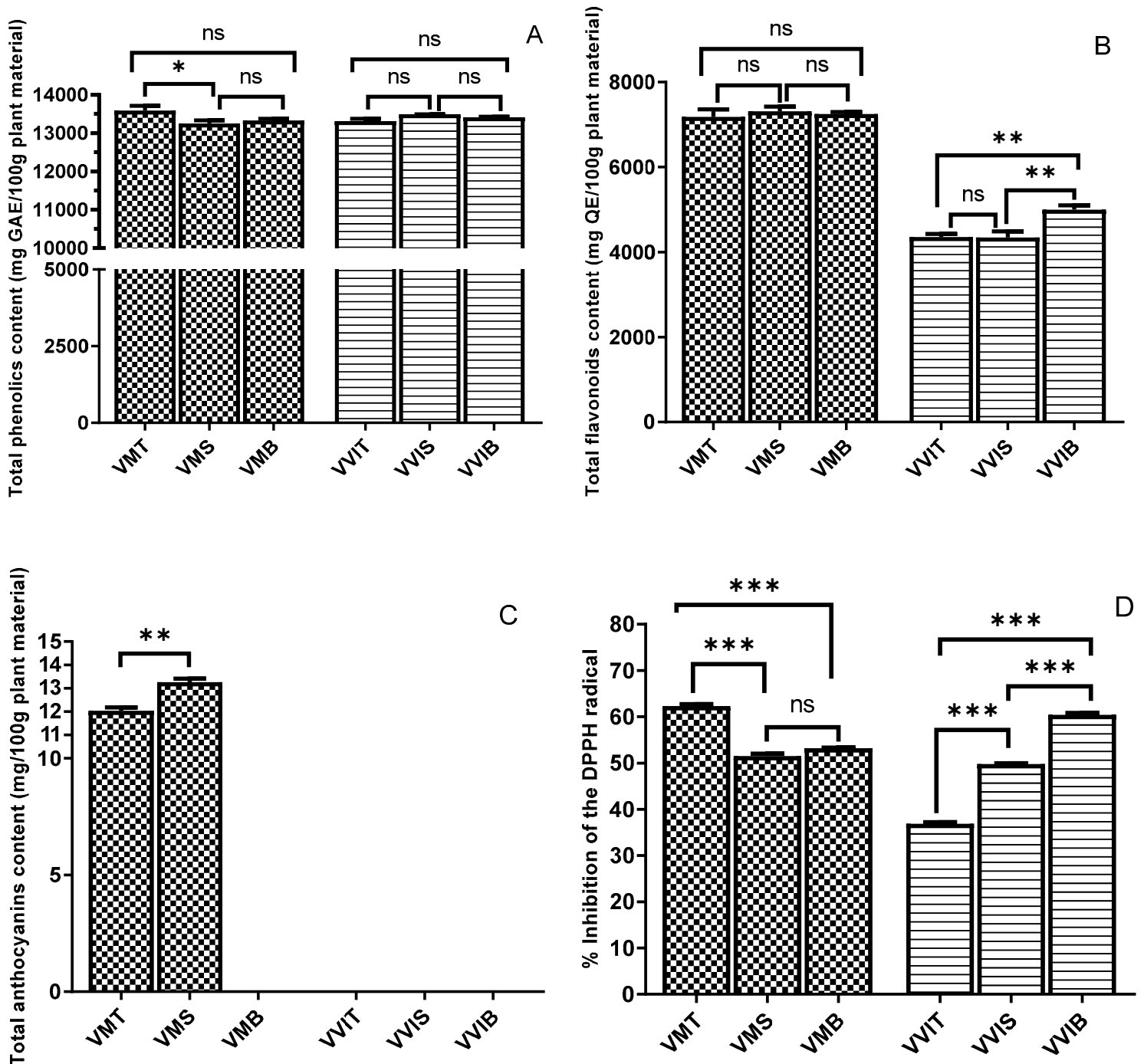

Figure 1. Total phenolic content (Folin-Ciocalteu method) (A), total flavonoids content (B), total anthocyanin content (C), and 2,2-diphenyl-1-picrylhydrazyl (DPPH) antioxidant activity (D) of the two species leave extracts, from all three locations. The total phenolic content of the extract is expressed as gallic acid equivalents (GAE) in $\mathrm{mg} / 100 \mathrm{~g}$ plant material. Total flavonoid content is expressed as quercetin equivalents $(\mathrm{QE})$ in $\mathrm{mg} / 100 \mathrm{~g}$ plant material. The DPPH activity was expressed as percentage inhibition (I\%). Values are reported as mean \pm SD of triplicate determinations and different symbols $(*, * *, * * *)$ indicate significant differences $(p<0.05)$ between the three different locations for each of the two species leave extracts, separately (one-way analysis of variance (ANOVA), multiple comparison tests, Tukey multiple range tests), while symbol (ns) indicate no significant difference. VMT, V. myrtillus leaves from Turda; VMS, V. myrtillus leaves from Smida; VMB, V. myrtillus leaves from Borsa; VVIT, V. vitis-idaea leaves from Turda; VVIS, V. vitis-idaea leaves from Smida; VVIB, V. vitis-idaea leaves from Borsa.

Figure 1B presents the TFC of the leaves extracts from both examined species. Among the studied bilberry leaves, there was no statistical difference with the habitat variation, with all three extracts having similar levels of approximately $7300 \mathrm{mg}$ QE/100 plant material. The bilberry species had twofold higher TFC when compared with lingonberry. This may be explained by the fact that chromatographic profiles of flavonoids, but not only them, are different among bilberry, blueberry, lingonberry, and cranberry $[66,67]$. In the case of lingonberry extracts, the VVIB registered the highest value (4994.18 $\pm 8.03 \mathrm{mg} \mathrm{QE} / 100$ plant material), being statistically different from the other two habitats. Uleberg et al. [37] found that the amount of flavan-3-ols was higher in bilberries growing at lower 
temperatures, a fact that might explain why Borsa habitat, with lower temperatures (ranging between $13^{\circ} \mathrm{C}$ and $8{ }^{\circ} \mathrm{C}$ ), registered higher amounts. In the study of Mikulic-Petkovsek et al. [40], low levels of flavanols were found in fruits collected in shaded forests characterized by a low photosynthetic active radiation (PAR), and high flavanol amounts in bilberries from sun-exposed locations with high PAR. Jaakola et al. [36] reported that the levels of flavan-3-ols were significantly higher in bilberry leaves exposed to direct sunlight. Considering that Borsa collection place had a good solar exposure when compared with partial or moderate exposure in the other two habitats, these previous findings might explain our results.

Other articles $[60,63]$ reported that increased solar exposure by higher altitudes contributes directly to increased flavonoids content in plants, which is partially true in our study considering that Borsa location (850 $\mathrm{m}$ altitude) had the highest level, and Smida location (1100 m) did not. Moreover, another study investigating the bilberry leaves concluded that leaves collected from open and forest areas showed that synthesis and accumulation of flavonoids were delayed in the forest compared with the high light open sites [24]. Several flavonoids and hydroxycinnamic acids act as characteristic UV shields and contribute to the plants' protective mechanism determined by high irradiation sites [60].

\subsection{Total Anthocyanin Content}

To our knowledge, this is the first study investigating the variation of the amounts of anthocyanins in wild-grown bilberries and lingonberries leaves in correlation to the geographical habitat. According to Figure 1C, only bilberry leaves via VMT and VMS extracts were found to have anthocyanin content. The anthocyanin profile contained small amounts of cyanidin glycosides, whereas VMS registered the highest level, precisely $13.29 \pm 0.13 \mathrm{mg} / 100 \mathrm{~g}$ plant material. Our results matched well with the results of a previous comparison of eastern and southern European plants with those from Scandinavia [68], suggesting that a higher altitude may provide an increased sunlight exposure, and thus a higher anthocyanins content. The low levels of total anthocyanin content might be owing to a non-specificity in the leaves of berries when compared with the fruits.

\subsection{DPPH Antioxidant Activity}

The percentage inhibition of the DPPH radicals for tested leaf extracts is shown in Figure 1D. For bilberry leaves, VMT showed the best radical scavenging capacity based on the DPPH assay expressed as percentage inhibition of DPPH radicals (also as Trolox equivalents, precisely $310.74 \mathrm{mMT} / 100 \mathrm{~g}$ ), while in the case of lingonberry leaves, the VVIB had the highest percentage inhibition of the DPPH radicals (and as Trolox equivalents, precisely $320.83 \mathrm{mMT} / 100 \mathrm{~g}$ ). These results could be explained by the highest value registered for TPC, in the case of bilberry leaves, and considering the well-known correlation between increased phenolic content and strong antioxidant capacity, whereas for VVIB, the highest TFC value reported may be responsible for the scavenging capacity, as previously reported in the literature [69]. Previous articles have reported that more solar exposure at increased altitude contributed to elevated biosynthesis of ortho-dihydroxylated flavonoids [34,63], as well as a better radical scavenger capacity [70]. In the case of lingonberry leaves, flavanols, flavonols, and caffeic acid derivatives bring highly antioxidant 1,2-dihydroxyphenyl moieties, whereas coumaric acid derivatives display the less antioxidant monohydroxyphenyl moiety. For similar phenolic contents in the case of lingonberry leaves, the $V$. vitis-idaea leaves from Turda (VVIT) present significantly lower antioxidant capacity than both VVIS (-26\%) and VVIB (-39\%) (Figure 1D). Concerning the higher levels of flavanols, and precisely of procyanidin dimers and procyanidin trimer, compared with VVIT, as well as for VVIB, a significant contribution via feruloylquinic acid might explain the differences. Extension and terminal epicatechin units in flavanols were already proven to be similarly reactive in the quenching of the nitrogen-centered DPPH radical [71]. In the study of Tian et al. [59], the DPPH radical scavenging capacity of the berry leaf extracts varied among species and cultivars, whereas within $10 \mathrm{~min}$, all the leaf extracts succeeded to capture around $80 \%$ of DPPH radicals. 
The difference in reactivity of leaf extracts, from the three different habitats, in the DPPH test can be attributed to their varying contents in polyphenols containing dihydroxyphenyl moieties, molecular sizes, like for flavanols [14], or the presence of unidentified antioxidant substances. Soobrattee et al. [72] classified the antioxidant activity in the following order: procyanidin dimer $>$ flavan-3-ols $>$ flavonols $>$ hydroxycinnamic acids $>$ simple phenolic acids. Heim et al. [73] explained why the proanthocyanidins (procyanidin dimers and procyanidin trimer) as oligomers and polymers of flavan-3-ols exhibit stronger DPPH capacity, namely owing to more catechol groups, coupled with C3-OH and C4-C8 linkage.

\subsection{Assessment of Antimicrobial Capacity}

The studied leaves extract registered antibacterial and antifungal capacity towards bacteria and fungal strains. The results of MIC are described in Table 2, and those of MBC are provided in Table 3, for both bacteria and fungi strains. An important range of bacteriostatic effects of the bilberry and lingonberry leaves extracts was reported, depending on the tested strain.

Table 2. Minimum inhibitory concentration (MIC) of bilberry and lingonberry leaves expressed as $\mathrm{mg} / \mathrm{mL}$.

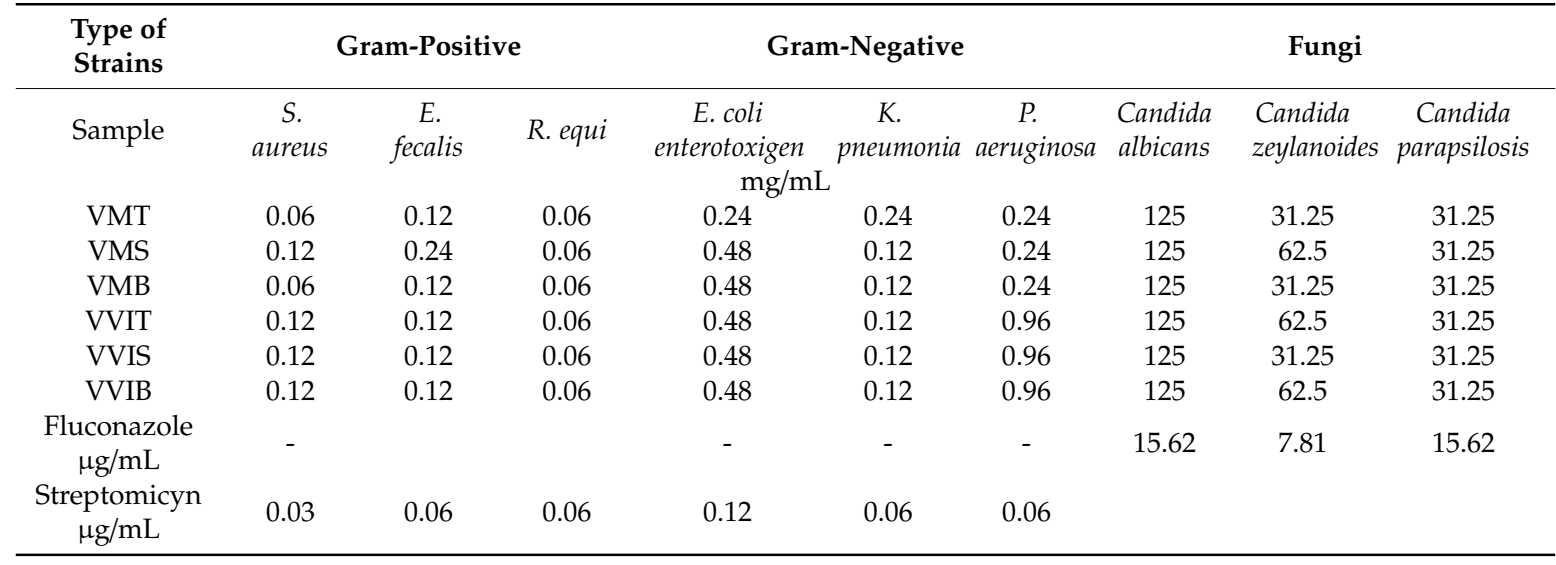

Table 3. Minimum bactericidal/fungicidal concentration (MBC/MFC) of bilberry and lingonberry leaves expressed as $\mathrm{mg} / \mathrm{mL}$.

\begin{tabular}{|c|c|c|c|c|c|c|c|c|c|}
\hline \multirow{2}{*}{$\begin{array}{l}\text { Type of } \\
\text { Strains }\end{array}$} & \multicolumn{3}{|c|}{ Gram-Positive } & \multicolumn{3}{|c|}{ Gram-Negative } & \multicolumn{3}{|c|}{ Fungi } \\
\hline & $\begin{array}{c}S . \\
\text { aureus }\end{array}$ & $\begin{array}{c}\text { E. } \\
\text { fecalis }\end{array}$ & R. equi & $\begin{array}{c}\text { E. coli } \\
\text { enterotoxigen } \\
\mathrm{mg} / \mathrm{mL}\end{array}$ & $\begin{array}{c}\text { K. } \\
\text { pneumonia }\end{array}$ & $\begin{array}{c}P . \\
\text { aeruginosa }\end{array}$ & $\begin{array}{l}\text { Candida } \\
\text { albicans }\end{array}$ & $\begin{array}{l}\text { Candida } \\
\text { zeylanoides }\end{array}$ & $\begin{array}{c}\text { Candida } \\
\text { parapsilosis }\end{array}$ \\
\hline VMT & 0.12 & 0.24 & 0.12 & 0.48 & 0.48 & 0.48 & 250 & 62.5 & 62.5 \\
\hline VMS & 0.24 & 0.48 & 0.12 & 0.96 & 0.24 & 0.48 & 250 & 125 & 62.5 \\
\hline VVIS & 0.24 & 0.24 & 0.12 & 0.96 & 0.24 & 1.92 & 250 & 62.5 & 62.5 \\
\hline VVIB & 0.24 & 0.24 & 0.12 & 0.96 & 0.24 & 1.92 & 250 & 125 & 62.5 \\
\hline $\begin{array}{l}\text { Fluconazole } \\
\mu \mathrm{g} / \mathrm{mL}\end{array}$ & - & & & - & - & - & 31.24 & 15.62 & 31.24 \\
\hline $\begin{array}{l}\text { Streptomicyn } \\
\mu \mathrm{g} / \mathrm{mL}\end{array}$ & 0.06 & 0.12 & 0.12 & 0.24 & 0.12 & 0.12 & & & \\
\hline
\end{tabular}

In the case of bilberry leaves, towards $S$. aureus, the best antibacterial activity was registered for both VMT and VMB (MIC $=0.06$ and $\mathrm{MBC}=0.12 \mathrm{mg} / \mathrm{mL})$. This result may be because of the increased TPC, considering that several studies underlined the fact that polyphenols may attack an important number of bacteria, and the antimicrobial capacity depends on interactions between polyphenols and bacterial cell surface [74,75]. R. equi was the most sensitive strain towards all the bilberry extracts, whereas E. faecalis Gram-positive strain was the most resistant one. 
Towards the lingonberry extracts, S. aureus and E. faecalis exhibited a higher resistance in comparison with $R$. equi. Considering the Gram-negative strains, E. coli enterotoxigen was not as sensitive as K. pneumonia and P. aeruginosa towards extracts' antibacterial effects. In the case of lingonberry species, the same antibacterial pattern was registered as for Gram-positive ones.

The highest inhibitory activity among bilberry species against all the strains is attributed to the VMT and VMB, while for lingonberry, it seems that natural habitat conditions did not influence the antibacterial effect, but the antifungal effect, only in the case of Candida zeylanoides. It can be concluded that the Gram-positive strains were much more sensitive to all the tested extracts when compared with the Gram-negative ones.

There are only a few studies reporting the antibacterial capacity of bilberry and lingonberry species. In vitro antimicrobial effect of flavonol glycosides, anthocyanins, procyanidins, and flavan-3-ols groups derived from lingonberry juice were demonstrated towards S. mutans and F. nucleatum [76]. Moreover, the antibacterial capacity of fruits and leaves of bilberry in different types of solvents, like water, ethanol, and ethyl acetate, was tested on E. coli, E. faecalis, and P. vulgaris, and it was reported that all extracts had a higher effect towards E. faecalis and P. vulgaris [77]. The study of Tian et al. [59] demonstrated that the extracts of lingonberry leaves, hawthorn leaves, sea buckthorn leaves, Saskatoon leaves, and raspberry leaves registered high inhibitory effects towards S. aureus, L. monocytogenes, and B. cereus. The findings also suggested increased sensitivity of Gram-positive in contrast to Gram-negative bacteria to the phenolic extracts. Moreover, the same study found that the TPC and the content of non-flavonoid phenolics presented a stronger correlation with the inhibitory effects on S. aureus and Bacillus cereus when compared with TFC. Another study [78] established that lingonberry fruit extracts containing mainly type-A proanthocyanidins may be bactericidal against $S$. aureus or inhibit the hemagglutination of E. coli. Considering that both species had important amounts of proanthocyanidins (procyanidin dimer II, procyanidin trimer), this hypothesis could explain the antibacterial effects on $S$. aureus and E. coli. Several mechanisms of action in the growth inhibition of bacteria are involved, such as destabilization of the cytoplasmic membrane, permeabilization of the plasma membrane, inhibition of extracellular microbial enzymes, direct actions on microbial metabolism, and deprivation of the substrates required for microbial growth [79].

Regarding the antifungal capacity, both species, in the case of all three types of habitats, had the same effect towards Candida albicans, precisely none (MIC $=125$ and $\mathrm{MFC}=250 \mathrm{mg} / \mathrm{mL}$ ) when compared with control Fluconazole (MIC $=15.62$ and $\mathrm{MFC}=31.25 \mathrm{mg} / \mathrm{mL}$ ), with the highest antifungal effect towards Candida parapsilosis (MIC $=31.25$ and $\mathrm{MFC}=62.5$ ). Against Candida zeylanoides, the highest inhibitory potential was registered by VMB and VMT (MIC $=31.25$ and $\mathrm{MFC}=62.5 \mathrm{mg} / \mathrm{mL}$ ), as well as VVIS, respectively. A possible explanation of why Candida species were not sensitive to our berry leaf extracts could be explained by the lack of ellagitannins, reported previously as the main antimicrobial compounds against these microorganisms [80].

\subsection{Assessment of Antimutagenic Effects of Bilberry and Lingonberry Leaves}

The investigation and discovery of antimutagenic properties of plants are of great practical and therapeutic importance in pharmacology and medicine. Research over the past few years has revealed that mutation has a key role in carcinogenesis [81]. The wild bilberry and lingonberry leaf extracts were tested for their antimutagenic activity, considering our recent review study on their significant antioxidant capacity [1]. The influence of the habitat conditions, as well as the type of Vaccinium species, had an important influence on the number of revertants in S. typhimurium TA98 and TA100. The antimutagenicity potential of both species towards S. typhimurium TA98 and TA100 is reported in Table 4, whereas the tested direct-acting mutagens were 4-NPD for TA98 and sodium azide (NaN3) for TA 100 . 
Table 4. Antimutagenicity capacity towards Salmonella typhimurium TA98 and TA100 strains.

\begin{tabular}{|c|c|c|c|c|}
\hline \multirow{3}{*}{ Samples } & \multicolumn{4}{|c|}{ Number of Revertants } \\
\hline & \multicolumn{2}{|c|}{ TA 98} & \multicolumn{2}{|c|}{ TA100 } \\
\hline & Mean \pm S.D & Inhibition \% & Mean \pm S.D & Inhibition \% \\
\hline Negative Control & $9.25 \pm 3.6^{\mathrm{a}}$ & & $9.25 \pm 2.4^{\mathrm{a}}$ & \\
\hline VMT & $132 \pm 3.2$ & 31.95 & $198 \pm 4.2$ & 43.26 \\
\hline VMS & $133 \pm 4.4$ & 31.44 & $201 \pm 6.3$ & 42.4 \\
\hline VMB & $137 \pm 3.6$ & 29.38 & $202 \pm 5.4$ & 42.12 \\
\hline VVIT & $144 \pm 4.7$ & 25.77 & $223 \pm 2.6$ & 36.1 \\
\hline VVIS & $145 \pm 2.1$ & 25.25 & $245 \pm 4.3$ & 29.79 \\
\hline VVIB & $144 \pm 5.9$ & 25.77 & $234 \pm 7.9$ & 32.95 \\
\hline $4-\mathrm{NPD}^{\mathrm{b}}$ & $194 \pm 3.3$ & - & - & - \\
\hline $\mathrm{NaN}_{3} \mathrm{~b}$ & - & - & $349 \pm 15.22$ & - \\
\hline
\end{tabular}

${ }^{a}$ Values expressed are means \pm S.D of three replications. ${ }^{b}$ 4-nitro-ophenylenediamine (4-NPD) and $\mathrm{NaN}_{3}$ were used as positive controls for Salmonella thyphimurium TA98 and TA100 strains, respectively.

Concerning S. typhimurium TA98, the leaf extracts proved to significantly inhibit the number of revertants of strain TA98 induced by 4-NPD. Therefore, moderate antimutagenic activity was reported for both types of species, whereas the higher inhibition was registered by the bilberry leaves, precisely VMT (31.95\%), closely followed by VMS (31.44\%). A possible explanation for this could be the fact that the VMT sample had an increased scavenging capacity, as the literature constantly links the antioxidant potential with the antimutagenic capacity of different types of plant extracts $[82,83]$. Moderate inhibition of around $25 \%$ was registered by all the lingonberry types of leaves, a fact that might be explained by the lack of statistically significant levels of TPC among the three extracts.

Towards TA100, both types of species registered a higher antimutagenic activity, suggesting that S. typhimurium TA100 was much more sensitive to Vaccinium-type of leaf extracts. Following Table 4 , all three types of bilberry leaves showed a strong inhibition capacity $(>40 \%)$, whereas the best inhibition was exhibited by the VMT (43.26\%) extract, closely followed by VMS and VMB. Regarding the lingonberry leaves, all of the extracts proved a moderate antimutagenic effect, whereas the VVIT extract inhibited the mutagenic effect of sodium azide of more than $36 \%$, while the VVIS had the lowest inhibition percentage $(29.79 \%)$. The best antimutagenic capacity was registered toward the strain S. typhimurium TA100 by all the leaf extracts.

In the case of both species, all the above-mentioned favorable effects are more likely to be associated with a high content of flavanols and flavonols, which significantly decrease the mutagenic activity of the standard mutagens examined. To the best of our knowledge, this is the first study evaluating the antimutagenic activity of Nord-West Romanian wild bilberry and lingonberry leaves, thus with significant novelty for the present paper. Moreover, the literature lacks in studies investigating this specific features of bilberry and lingonberry fruits or leaves. In the study of Smith et al. [84], the antimutagenic activity of different berry extracts was investigated. Among the tested berries were strawberry, raspberry, and blueberry of different fresh cultivars, and in several kinds of solvents $\left(\mathrm{H}_{2} \mathrm{O}\right.$, ethanol, methanol). The antimutagenic inhibition range was between $23 \%$ and $53 \%$. Another study [85] investigating the capacity to prevent mutation induced by two promutagenic dietary quinolines, namely MeIQ and 4-NQO of the V. floribundum and V. myrtillus berries extracts, reported being inactive at concentrations up to $1000 \mathrm{~g} /$ plate. In the recent review study on flavonoids' bioactivity [86], it was reported that plant flavonoids exhibit an important antimutagenic activity. Moreover, cranberry (V. macrocarpon), as a significant source of polyphenols, has been reported within vitro antimutagenic properties [2,87].

Therefore, regarding the existing data, we can state that the berries contain anthocyanins and procyanidins, constantly reported for their strong antioxidative activity, leading to both in vitro and in vivo antibacterial and antimutagenic activities [88]. In this study, the hydroethanolic extracts from leaves of $V$. myrtillus L. and V. vitis-idaea L. did inhibit the mutations on the Ames Salmonella test. 
Besides, the present study has shown for the first time that hydroethanolic extracts from leaves of wild bilberry and lingonberry are a promising source for its antimutagenic compounds. These results indicate that it may be considered to be a safe and useful agent for the prevention of mutations.

\section{Conclusions}

The influence of natural habitats on the level of individual phenolic compounds and biological activities were examined, and considerable variations in phenolic profile and significant differences of bioactivities between bilberry and lingonberry leaves, collected from three different locations, were observed.

This study reports a qualitative analysis of bilberry and lingonberry leaves with structures proposed for 21 phenolic compounds. Quantitative analysis revealed that flavonoids class contribute more than half of the phenolic pool in leaves; whereas for bilberry species, rutin represents $50 \%$ of this subclass; and for lingonberry species, the flavanols comprise the majority via gallocatechin, epigallocatechin, catechin, and procyanidin trimer. Of significant novelty was the antimutagenic testing among these species, at different habitats, concluding that bilberry leaves have a stronger antimutagenic capacity, whereas better sun exposure may contribute to an increased flavonols synthesis, leading to better antioxidant and antimutagenic activities. Regarding the antimicrobial effects of the studies species, the Gram-positive bacteria were more susceptible to the activity of the extract, presenting high antibacterial effects, whereas the antifungal capacity was low.

Thus, the hypothesis that plants from higher altitudes contain higher amounts of radical scavenging compounds as a result of their exposure to more severe climatic conditions including enhanced solar radiation cannot be affirmed in general. On the basis of our results, distinct differences between the amounts of phenolic compounds due to habitat-derived conditions (altitude, solar exposure, temperature range, and so on) can be expected at least in the case of the flavanols, flavonols, hydroxycinnamic acids, and anthocyanins investigated in these species.

Author Contributions: Conceptualization, B.-E.S., and G.C.; methodology, B.-E.S.; software, L.F.C.; validation, G.C., A.M., and D.C.V.; investigation, B.-E.S., F.F., and F.R.; resources, D.C.V.; writing-original draft preparation, B.-E.S. and L.F.C.; writing - review and editing, G.C., A.M., and D.C.V.; supervision, G.C.; project administration, D.C.V.; funding acquisition, D.C.V. All authors have read and agreed to the published version of the manuscript.

Funding: This research was funded by MCI-UEFISCDI, grant number 2 PCCDI, Proiect PN-III-P1-1.2PCCDI-2017-0056, and the publication was funded by 37 PFE.

Conflicts of Interest: The authors declare no conflict of interest.

\section{References}

1. Ștefănescu, B.E.; Szabo, K.; Mocan, A.; Crişan, G. Phenolic Compounds from Five Ericaceae Species Leaves and Their Related Bioavailability and Health Benefits. Molecules 2019, 24, 2046. [CrossRef] [PubMed]

2. Del Rio, D.; Rodriguez-Mateos, A.; Spencer, J.P.E.; Tognolini, M.; Borges, G.; Crozier, A. Dietary (Poly)phenolics in Human Health: Structures, Bioavailability, and Evidence of Protective Effects Against Chronic Diseases. Antioxid. Redox Signal. 2012, 18, 1818-1892. [CrossRef] [PubMed]

3. Shahidi, F.; Ambigaipalan, P. Phenolics and polyphenolics in foods, beverages and spices: Antioxidant activity and health effects-A review. J. Funct. Foods 2015, 18, 820-897. [CrossRef]

4. Shahidi, F.; Yeo, J.; Shahidi, F.; Yeo, J. Bioactivities of Phenolics by Focusing on Suppression of Chronic Diseases: A Review. Int. J. Mol. Sci. 2018, 19, 1573. [CrossRef] [PubMed]

5. Abbas, M.; Saeed, F.; Anjum, F.M.; Afzaal, M.; Tufail, T.; Bashir, M.S.; Ishtiaq, A.; Hussain, S.; Suleria, H.A.R. Natural polyphenols: An overview. Int. J. Food Prop. 2017, 20, 1689-1699. [CrossRef]

6. Popa, D.-S.; Bolfa, P.; Kiss, B.; Vlase, L.; Păltinean, R.; Pop, A.; Cătoi, C.; Crişan, G.; Loghin, F. Influence of Genista Tinctoria L or Methylparaben on Subchronic Toxicity of Bisphenol A in Rats. Biomed. Environ. Sci. 2014, 27, 85-96. [CrossRef] 
7. Pop, A.; Berce, C.; Bolfa, P.F.; Cătoi, C.; Dumitrescu, I.-B.; Silaghi-Dumitrescu, L.; Loghin, F. Evaluation of the possible endocrine disruptive effect of butylated hydroxyanisole, butylated hydroxytoluene and propyl gallate in immature female rats. Farmacia 2013, 61, 202-211.

8. Dai, J.; Mumper, R.J. Plant phenolics: Extraction, analysis and their antioxidant and anticancer properties. Mol. Basel Switz. 2010, 15, 7313-7352. [CrossRef]

9. Călinoiu, L.F.; Vodnar, D.C. Whole Grains and Phenolic Acids: A Review on Bioactivity, Functionality, Health Benefits and Bioavailability. Nutrients 2018, 10, 1615. [CrossRef]

10. Calinoiu, L.-F.; Mitrea, L.; Precup, G.; Bindea, M.; Rusu, B.; Dulf, F.-V.; Stefanescu, B.-E.; Vodnar, D.-C. Characterization of Grape and Apple Peel Wastes' Bioactive Compounds and Their Increased Bioavailability After Exposure to Thermal Process. Bull. Univ. Agric. Sci. Vet. Med. Cluj-Napoca-Food Sci. Technol. 2017, 74, 80-89. [CrossRef]

11. Călinoiu, L.F.; Cătoi, A.-F.; Vodnar, D.C. Solid-State Yeast Fermented Wheat and Oat Bran as A Route for Delivery of Antioxidants. Antioxidants 2019, 8, 372. [CrossRef] [PubMed]

12. Martins, N.; Barros, L.; Ferreira, I.C.F.R. In vivo antioxidant activity of phenolic compounds: Facts and gaps. Trends Food Sci. Technol. 2016, 48, 1-12. [CrossRef]

13. Calinoiu, L.F.; Farcas, A.; Socaci, S.; Vodnar, D.C. Innovative Sources; Galanakis, C.M., Ed.; Academic Press Ltd-Elsevier Science Ltd.: London, UK, 2019; pp. 235-265. ISBN 978-0-12-817516-3.

14. Bujor, O.C.; Ginies, C.; Popa, V.I.; Dufour, C. Phenolic compounds and antioxidant activity of lingonberry (Vaccinium vitis-idaea L.) leaf, stem and fruit at different harvest periods. Food Chem. 2018, 252, 356-365. [CrossRef] [PubMed]

15. Ancillotti, C.; Ciofi, L.; Rossini, D.; Chiuminatto, U.; Stahl-Zeng, J.; Orlandini, S.; Furlanetto, S.; Del Bubba, M. Liquid chromatographic/electrospray ionization quadrupole/time of flight tandem mass spectrometric study of polyphenolic composition of different Vaccinium berry species and their comparative evaluation. Anal. Bioanal. Chem. 2017, 409, 1347-1368. [CrossRef] [PubMed]

16. Tian, Y.; Liimatainen, J.; Alanne, A.L.; Lindstedt, A.; Liu, P.; Sinkkonen, J.; Kallio, H.; Yang, B. Phenolic compounds extracted by acidic aqueous ethanol from berries and leaves of different berry plants. Food Chem. 2017, 220, 266-281. [CrossRef]

17. Grace, M.H.; Esposito, D.; Dunlap, K.L.; Lila, M.A. Comparative Analysis of Phenolic Content and Profile, Antioxidant Capacity, and Anti-inflammatory Bioactivity in Wild Alaskan and Commercial Vaccinium Berries. J. Agric. Food Chem. 2014, 62, 4007-4017. [CrossRef]

18. Ermis, E.; Hertel, C.; Schneider, C.; Carle, R.; Stintzing, F.; Schmidt, H. Characterization of in vitro antifungal activities of small and American cranberry (Vaccinium oxycoccos L. and V. macrocarpon Aiton) and lingonberry (Vaccinium vitis-idaea L.) concentrates in sugar reduced fruit spreads. Int. J. Food Microbiol. 2015, 204, 111-117. [CrossRef]

19. Bujor, O.C.; Le Bourvellec, C.; Volf, I.; Popa, V.I.; Dufour, C. Seasonal variations of the phenolic constituents in bilberry (Vaccinium myrtillus L.) leaves, stems and fruits, and their antioxidant activity. Food Chem. 2016, 213, 58-68. [CrossRef]

20. Bujor, O.-C.; Tanase, C.; Popa, M.E. Phenolic Antioxidants in Aerial Parts of Wild Vaccinium Species: Towards Pharmaceutical and Biological Properties. Antioxid. Basel Switz. 2019, 8, 649. [CrossRef]

21. Vyas, P.; Kalidindi, S.; Chibrikova, L.; Igamberdiev, A.U.; Weber, J.T. Chemical analysis and effect of blueberry and lingonberry fruits and leaves against glutamate-mediated excitotoxicity. J. Agric. Food Chem. 2013, 61, 7769-7776. [CrossRef]

22. Teleszko, M.; Wojdyło, A. Comparison of phenolic compounds and antioxidant potential between selected edible fruits and their leaves. J. Funct. Foods 2015, 14, 736-746. [CrossRef]

23. Hokkanen, J.; Mattila, S.; Jaakola, L.; Pirttila, A.M.; Tolonen, A. Identification of phenolic compounds from lingonberry (Vaccinium vitis-idaea L.), Bilberry (Vaccinium myrtillus L.) and Hybrid Bilberry (Vaccinium $\mathrm{x}$ intermedium Ruthe L.) Leaves. J. Agric. Food Chem. 2009, 57, 9437-9447. [CrossRef] [PubMed]

24. Martz, F.; Jaakola, L.; Julkunen-Tiitto, R.; Stark, S. Phenolic Composition and Antioxidant Capacity of Bilberry (Vaccinium myrtillus) Leaves in Northern Europe Following Foliar Development and Along Environmental Gradients. J. Chem. Ecol. 2010, 36, 1017-1028. [CrossRef] [PubMed]

25. Liu, P.; Lindstedt, A.; Markkinen, N.; Sinkkonen, J.; Suomela, J.-P.; Yang, B. Characterization of Metabolite Profiles of Leaves of Bilberry (Vaccinium myrtillus L.) and Lingonberry (Vaccinium vitis-idaea L.). J. Agric. Food Chem. 2014, 62, 12015-12026. [CrossRef] 
26. Piterà, F. Compedio di Gemmoterapia Clinica; De Ferrari: Genova, Italy, 1994.

27. Ieri, F.; Martini, S.; Innocenti, M.; Mulinacci, N. Phenolic distribution in liquid preparations of Vaccinium myrtillus L. and Vaccinium vitis idaea L. Phytochem. Anal. 2013, 24, 467-475. [CrossRef]

28. Cignarella, A.; Nastasi, M.; Cavalli, E.; Puglisi, L. Novel lipid-lowering properties of Vaccinium myrtillus L. leaves, a traditional antidiabetic treatment, in several models of rat dyslipidaemia: A comparison with ciprofibrate. Thromb. Res. 1996, 84, 311-322. [CrossRef]

29. Wang, X.; Sun, H.; Fan, Y.; Li, L.; Makino, T.; Kano, Y. Analysis and bioactive evaluation of the compounds absorbed into blood after oral administration of the extracts of Vaccinium vitis-idaea in rat. Biol. Pharm. Bull. 2005, 28, 1106-1108. [CrossRef]

30. Raudone, L.; Vilkickyte, G.; Pitkauskaite, L.; Raudonis, R.; Vainoriene, R.; Motiekaityte, V. Antioxidant Activities of Vaccinium vitis-idaea L. Leaves within Cultivars and Their Phenolic Compounds. Molecules 2019, 24, 844. [CrossRef]

31. Alam, Z.; Morales, H.R.; Roncal, J. Environmental conditions affect phenolic content and antioxidant capacity of leaves and fruit in wild partridgeberry (Vaccinium vitis-idaea). Botany 2016, 94, 509-521. [CrossRef]

32. Körner, C. Alpine Plant Life: Functional Plant Ecology of High Mountain Ecosystems; with 47 Tables; Springer Science \& Business Media: Berlin/Heidelberg, Germany, 2003; ISBN 978-3-540-00347-2.

33. Bilger, W.; Rolland, M.; Nybakken, L. UV screening in higher plants induced by low temperature in the absence of UV-B radiation. Photochem. Photobiol. Sci. 2007, 6, 190-195. [CrossRef]

34. Markham, K.R.; Tanner, G.J.; Caasi-Lit, M.; Whitecross, M.I.; Nayudu, M.; Mitchell, K.A. Possible protective role for $3^{\prime}, 4^{\prime}$-dihydroxyflavones induced by enhanced UV-B in a UV-tolerant rice cultivar. Phytochemistry 1998, 49, 1913-1919. [CrossRef]

35. Wellmann, E. UV dose-dependent induction of enzymes related to flavonoid biosynthesis in cell suspension cultures of parsley. FEBS Lett. 1975, 51, 105-107. [CrossRef]

36. Jaakola, L.; Määttä-Riihinen, K.; Kärenlampi, S.; Hohtola, A. Activation of flavonoid biosynthesis by solar radiation in bilberry (Vaccinium myrtillus L.) leaves. Planta 2004, 218, 721-728. [CrossRef] [PubMed]

37. Uleberg, E.; Rohloff, J.; Jaakola, L.; Trôst, K.; Junttila, O.; Häggman, H.; Martinussen, I. Effects of Temperature and Photoperiod on Yield and Chemical Composition of Northern and Southern Clones of Bilberry (Vaccinium myrtillus L.). J. Agric. Food Chem. 2012, 60, 10406-10414. [CrossRef]

38. Åkerström, A.; Jaakola, L.; Bång, U.; Jäderlund, A. Effects of Latitude-Related Factors and Geographical Origin on Anthocyanidin Concentrations in Fruits of Vaccinium myrtillus L. (Bilberries). J. Agric. Food Chem. 2010, 58, 11939-11945. [CrossRef]

39. Jovančević, M.; Balijagić, J.; Menković, N.R.; Scaron, K.; avikin; Zdunić, G.M.; Janković, T.; Dekić-Ivanković, M. Analysis of phenolic compounds in wild populations of bilberry (Vaccinium myrtillus L.) from Montenegro. J. Med. Plant Res. 2011, 5, 910-914.

40. Mikulic-Petkovsek, M.; Schmitzer, V.; Slatnar, A.; Stampar, F.; Veberic, R. A comparison of fruit quality parameters of wild bilberry (Vaccinium myrtillus L.) growing at different locations. J. Sci. Food Agric. 2015, 95, 776-785. [CrossRef]

41. Meteoblue. Available online: https://www.meteoblue.com/ro/vreme/historyclimate/weatherarchive/turda rom\%C3\%A2nia_664460 (accessed on 4 June 2020).

42. Meteoromania. Available online: http://www.meteoromania.ro/servicii/date-meteorologice/arhiva-precipitatii/ (accessed on 4 June 2020).

43. Meteoblue. Available online: https://www.meteoblue.com/ro/vreme/historyclimate/weatherarchive/bor\% c5\%9fa_rom\%c3\%a2nia_684156 (accessed on 4 June 2020).

44. Dulf, F.V.; Vodnar, D.C.; Dulf, E.H.; Toşa, M.I. Total Phenolic Contents, Antioxidant Activities, and Lipid Fractions from Berry Pomaces Obtained by Solid-State Fermentation of Two Sambucus Species with Aspergillus niger. J. Agric. Food Chem. 2015, 63, 3489-3500. [CrossRef]

45. Dulf, F.V.; Vodnar, D.C.; Socaciu, C. Effects of solid-state fermentation with two filamentous fungi on the total phenolic contents, flavonoids, antioxidant activities and lipid fractions of plum fruit (Prunus domestica L.) by-products. Food Chem. 2016, 209, 27-36. [CrossRef]

46. Zhishen, J.; Mengcheng, T.; Jianming, W. The determination of flavonoid contents in mulberry and their scavenging effects on superoxide radicals. Food Chem. 1999, 64, 555-559. [CrossRef]

47. Giusti, M.M.; Wrolstad, R.E. Characterization and Measurement of Anthocyanins by UV-Visible Spectroscopy. Curr. Protoc. Food Anal. Chem. 2001, F1.2.1-F1.2.13. [CrossRef] 
48. Ebrahimabadi, A.H.; Mazoochi, A.; Kashi, F.J.; Djafari-Bidgoli, Z.; Batooli, H. Essential oil composition and antioxidant and antimicrobial properties of the aerial parts of Salvia eremophila Boiss. from Iran. Food Chem. Toxicol. Int. J. Publ. Br. Ind. Biol. Res. Assoc. 2010, 48, 1371-1376. [CrossRef] [PubMed]

49. Weinstein, M.P. Methods for Dilution Antimicrobial Susceptibility Tests for Bacteria that Grow Aerobically; Clinical and Laboratory Standards Institute (CLSI): Wayne, PA, USA, 2018; ISBN 978-1-56238-836-2.

50. Schwalbe, R.; Steele-Moore, L.; Goodwin, A.C. Antimicrobial Susceptibility Testing Protocols; CRC Press: Boca Raton, FL, USA, 2007; ISBN 978-1-4200-1449-5.

51. Alexander, B.D. Reference Method for Broth Dilution Antifungal Susceptibility Testing of Yeasts; Clinical and Laboratory Standards Institute: Wayne, PA, USA, 2017; ISBN 978-1-56238-826-3.

52. Maron, D.M.; Ames, B.N. Revised methods for the Salmonella mutagenicity test. Mutat. Res. Mutagen. Relat. Subj. 1983, 113, 173-215. [CrossRef]

53. Saraç, N.; Şen, B. Antioxidant, mutagenic, antimutagenic activities, and phenolic compounds of Liquidambar orientalis Mill. var. orientalis. Ind. Crops Prod. 2014, 53, 60-64. [CrossRef]

54. Ong, T.M.; Whong, W.Z.; Stewart, J.; Brockman, H.E. Chlorophyllin: A potent antimutagen against environmental and dietary complex mixtures. Mutat. Res. Lett. 1986, 173, 111-115. [CrossRef]

55. Evandri, M.G.; Battinelli, L.; Daniele, C.; Mastrangelo, S.; Bolle, P.; Mazzanti, G. The antimutagenic activity of Lavandula angustifolia (lavender) essential oil in the bacterial reverse mutation assay. Food Chem. Toxicol. 2005, 43, 1381-1387. [CrossRef]

56. Riihinen, K.; Jaakola, L.; Kärenlampi, S.; Hohtola, A. Organ-specific distribution of phenolic compounds in bilberry (Vaccinium myrtillus) and "northblue" blueberry (Vaccinium corymbosum x V. angustifolium). Food Chem. 2008, 110, 156-160. [CrossRef]

57. Dabbou, S.; Sifi, S.; Rjiba, I.; Esposto, S.; Taticchi, A.; Servili, M.; Montedoro, G.F.; Hammami, M. Effect of Pedoclimatic Conditions on the Chemical Composition of the Sigoise Olive Cultivar. Chem. Biodivers. 2010, 7, 898-908. [CrossRef]

58. Kähkönen, M.P.; Hopia, A.I.; Heinonen, M. Berry Phenolics and Their Antioxidant Activity. J. Agric. Food Chem. 2001, 49, 4076-4082. [CrossRef]

59. Tian, Y.; Puganen, A.; Alakomi, H.-L.; Uusitupa, A.; Saarela, M.; Yang, B. Antioxidative and antibacterial activities of aqueous ethanol extracts of berries, leaves, and branches of berry plants. Food Res. Int. 2018, 106, 291-303. [CrossRef]

60. Rieger, G.; Müller, M.; Guttenberger, H.; Bucar, F. Influence of Altitudinal Variation on the Content of Phenolic Compounds in Wild Populations of Calluna vulgaris, Sambucus nigra, and Vaccinium myrtillus. J. Agric. Food Chem. 2008, 56, 9080-9086. [CrossRef] [PubMed]

61. Bidel, L.P.R.; Meyer, S.; Goulas, Y.; Cadot, Y.; Cerovic, Z.G. Responses of epidermal phenolic compounds to light acclimation: In vivo qualitative and quantitative assessment using chlorophyll fluorescence excitation spectra in leaves of three woody species. J. Photochem. Photobiol. B 2007, 88, 163-179. [CrossRef] [PubMed]

62. Li, P.; Ma, F.; Cheng, L. Primary and secondary metabolism in the sun-exposed peel and the shaded peel of apple fruit. Physiol. Plant. 2013, 148, 9-24. [CrossRef] [PubMed]

63. Spitaler, R.; Winkler, A.; Lins, I.; Yanar, S.; Stuppner, H.; Zidorn, C. Altitudinal Variation of Phenolic Contents in Flowering Heads of Arnica montana cv. ARBO: A 3-Year Comparison. J. Chem. Ecol. 2008, 34, 369-375. [CrossRef] [PubMed]

64. Jakopic, J.; Stampar, F.; Veberic, R. The influence of exposure to light on the phenolic content of 'Fuji' apple. Sci. Hortic. 2009, 123, 234-239. [CrossRef]

65. Rosłon, W.; Osińska, E.; Pióro-Jabrucka, E.; Grabowska, A. Morphological and chemical variability of wild populations of bilberry (Vaccinium myrtillus L.). Pol. J. Environ. Stud. 2011, 20, 237-243.

66. Zheng, W.; Wang, S.Y. Oxygen Radical Absorbing Capacity of Phenolics in Blueberries, Cranberries, Chokeberries, and Lingonberries. J. Agric. Food Chem. 2003, 51, 502-509. [CrossRef]

67. Jaakola, L.; Määttä, K.; Pirttilä, A.M.; Törrönen, R.; Kärenlampi, S.; Hohtola, A. Expression of Genes Involved in Anthocyanin Biosynthesis in Relation to Anthocyanin, Proanthocyanidin, and Flavonol Levels during Bilberry Fruit Development. Plant Physiol. 2002, 130, 729-739. [CrossRef]

68. Määttä-Riihinen, K.R.; Kamal-Eldin, A.; Mattila, P.H.; González-Paramás, A.M.; Törrönen, A.R. Distribution and contents of phenolic compounds in eighteen Scandinavian berry species. J. Agric. Food Chem. 2004, 52, 4477-4486. [CrossRef] 
69. Szakiel, A.; Paczkowski, C.; Koivuniemi, H.; Huttunen, S. Comparison of the triterpenoid content of berries and leaves of lingonberry Vaccinium vitis-idaea from Finland and Poland. J. Agric. Food Chem. 2012, 60, 4994-5002. [CrossRef]

70. Rice-Evans, C.A.; Miller, N.J.; Paganga, G. Structure-antioxidant activity relationships of flavonoids and phenolic acids. Free Radic. Biol. Med. 1996, 20, 933-956. [CrossRef]

71. Goupy, P.; Dufour, C.; Loonis, M.; Dangles, O. Quantitative Kinetic Analysis of Hydrogen Transfer Reactions from Dietary Polyphenols to the DPPH Radical. J. Agric. Food Chem. 2003, 51, 615-622. [CrossRef] [PubMed]

72. Soobrattee, M.A.; Neergheen, V.S.; Luximon-Ramma, A.; Aruoma, O.I.; Bahorun, T. Phenolics as potential antioxidant therapeutic agents: Mechanism and actions. Mutat. Res. 2005, 579, 200-213. [CrossRef] [PubMed]

73. Heim, K.E.; Tagliaferro, A.R.; Bobilya, D.J. Flavonoid antioxidants: Chemistry, metabolism and structure-activity relationships. J. Nutr. Biochem. 2002, 13, 572-584. [CrossRef]

74. Bouarab-Chibane, L.; Forquet, V.; Lantéri, P.; Clément, Y.; Léonard-Akkari, L.; Oulahal, N.; Degraeve, P.; Bordes, C. Antibacterial Properties of Polyphenols: Characterization and QSAR (Quantitative Structure-Activity Relationship) Models. Front. Microbiol. 2019, 10. [CrossRef] [PubMed]

75. Coppo, E.; Marchese, A. Antibacterial activity of polyphenols. Curr. Pharm. Biotechnol. 2014, 15, 380-390. [CrossRef]

76. Riihinen, K.R.; Ou, Z.M.; Gödecke, T.; Lankin, D.C.; Pauli, G.F.; Wu, C.D. The antibiofilm activity of lingonberry flavonoids against oral pathogens is a case connected to residual complexity. Fitoterapia 2014, 97, 78-86. [CrossRef]

77. Vučić, D.M.; Petković, M.R.; Rodić-Grabovac, B.B.; Stefanović, O.D.; Vasić, S.M.; Čomić, L.R. Antibacterial and antioxidant activities of bilberry (Vaccinium myrtillus L.) in vitro. Afr. J. Microbiol. Res. 2013, 7, 5130-5136.

78. Kylli, P.; Nohynek, L.; Puupponen-Pimiä, R.; Westerlund-Wikström, B.; Leppänen, T.; Welling, J.; Moilanen, E.; Heinonen, M. Lingonberry (Vaccinium vitis-idaea) and European Cranberry (Vaccinium microcarpon) Proanthocyanidins: Isolation, Identification, and Bioactivities. J. Agric. Food Chem. 2011, 59, 3373-3384. [CrossRef]

79. Puupponen-Pimiä, R.; Nohynek, L.; Alakomi, H.-L.; Oksman-Caldentey, K.-M. Bioactive berry compoundsNovel tools against human pathogens. Appl. Microbiol. Biotechnol. 2005, 67, 8-18. [CrossRef]

80. Nohynek, L.J.; Alakomi, H.-L.; Kähkönen, M.P.; Heinonen, M.; Helander, I.M.; Oksman-Caldentey, K.-M.; Puupponen-Pimiä, R.H. Berry Phenolics: Antimicrobial Properties and Mechanisms of Action Against Severe Human Pathogens. Nutr. Cancer 2006, 54, 18-32. [CrossRef] [PubMed]

81. Zahin, M.; Aqil, F.; Ahmad, I. Broad spectrum antimutagenic activity of antioxidant active fraction of punica granatum L. peel extracts. Mutat. Res. 2010, 703, 99-107. [CrossRef] [PubMed]

82. Brindzová, L.; Zalibera, M.; Jakubík, T.; Mikulášová, M.; Takácsová, M.; Mošovská, S.; Rapta, P. Antimutagenic and Radical Scavenging Activity of Wheat Bran. Cereal Res. Commun. 2009, 37, 45-55. [CrossRef]

83. Călinoiu, L.F.; Vodnar, D.C. Thermal Processing for the Release of Phenolic Compounds from Wheat and Oat Bran. Biomolecules 2020, 10, 21. [CrossRef]

84. Hope Smith, S.; Tate, P.L.; Huang, G.; Magee, J.B.; Meepagala, K.M.; Wedge, D.E.; Larcom, L.L. Antimutagenic activity of berry extracts. J. Med. Food 2004, 7, 450-455. [CrossRef]

85. Prencipe, F.P.; Bruni, R.; Guerrini, A.; Rossi, D.; Benvenuti, S.; Pellati, F. Metabolite profiling of polyphenols in Vaccinium berries and determination of their chemopreventive properties. J. Pharm. Biomed. Anal. 2014, 89, 257-267. [CrossRef]

86. Panche, A.N.; Diwan, A.D.; Chandra, S.R. Flavonoids: An overview. J. Nutr. Sci. 2016, 5, e47. [CrossRef]

87. Côté, J.; Caillet, S.; Doyon, G.; Sylvain, J.-F.; Lacroix, M. Bioactive Compounds in Cranberries and their Biological Properties. Crit. Rev. Food Sci. Nutr. 2010, 50, 666-679. [CrossRef]

88. Jurikova, T.; Mlcek, J.; Skrovankova, S.; Sumczynski, D.; Sochor, J.; Hlavacova, I.; Snopek, L.; Orsavova, J. Fruits of Black Chokeberry Aronia melanocarpa in the Prevention of Chronic Diseases. Molecules 2017, $22,944$. [CrossRef]

(C) 2020 by the authors. Licensee MDPI, Basel, Switzerland. This article is an open access article distributed under the terms and conditions of the Creative Commons Attribution (CC BY) license (http://creativecommons.org/licenses/by/4.0/). 